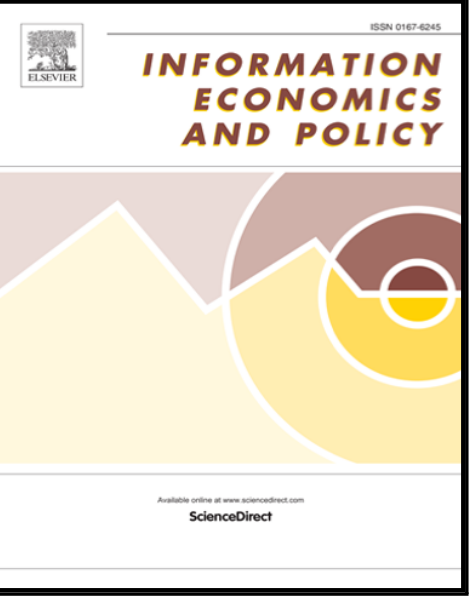

What Drives Pricing Behavior in Peer-to-Peer Markets? Evidence from the Carsharing Platform BlaBlaCar

Mehdi Farajallah, Robert G. Hammond, Thierry Pénard

PII: S0167-6245(17)30213-5

DOI: https://doi.org/10.1016/j.infoecopol.2019.01.002

Reference: IEPOL 822

To appear in: Information Economics and Policy

Received date: 28 November 2017

Revised date: $\quad 2$ December 2018

Accepted date: $\quad 10$ January 2019

Please cite this article as: Mehdi Farajallah, Robert G. Hammond, Thierry Pénard, What Drives Pricing Behavior in Peer-to-Peer Markets? Evidence from the Carsharing Platform BlaBlaCar, Information Economics and Policy (2019), doi: https://doi.org/10.1016/j.infoecopol.2019.01.002

This is a PDF file of an unedited manuscript that has been accepted for publication. As a service to our customers we are providing this early version of the manuscript. The manuscript will undergo copyediting, typesetting, and review of the resulting proof before it is published in its final form. Please note that during the production process errors may be discovered which could affect the content, and all legal disclaimers that apply to the journal pertain. 


\section{Highlights}

- Our paper investigates how prices are determined on peer-to-peer markets

- We analyze whether experience and reputation in sharing economy platforms have the same impact as in traditional markets

- We provide the first empirical analysis of the world's leading intercity carsharing platform, BlaBlaCar

- We show that more-experienced drivers on BlaBlaCar set lower prices and sell more seats than less-experienced drivers.

- We find evidence of discrimination against drivers of a minority group (Arabic drivers) that sell less seats on Blablacar. 


\title{
What Drives Pricing Behavior in Peer-to-Peer Markets? Evidence from the Carsharing Platform BlaBlaCar*
}

\author{
Mehdi Farajallah (Rennes School of Business) \\ Robert G. Hammond (North Carolina State University) \\ Thierry Pénard (CREM, University of Rennes 1)
}

November 2018

\begin{abstract}
We examine how price and demand are determined on peer-to-peer platforms and whether experience and reputation have the same impact as in traditional markets. We use data from the world's leading intercity carsharing platform, BlaBlaCar, which connects drivers with empty seats to riders. We find that pricing decisions evolve as drivers gain experience with the platform. More-experienced drivers set lower prices and, controlling for price, sell more seats. Our interpretation is that more-experienced drivers on BlaBlaCar learn to lower their prices as they gain experience; accordingly, more-experienced drivers earn more revenue per trip. In total, our results suggest that peer-to-peer markets such as BlaBlaCar share some characteristics with other types of peer-to-peer markets such as eBay but remain a unique and rich setting in which there are many new insights to be gained.
\end{abstract}

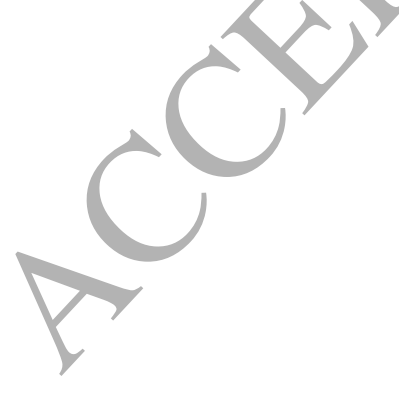

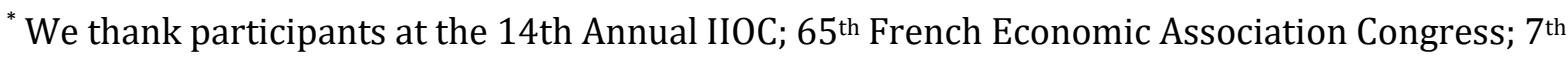
Searle Center Conference on Internet Commerce and Innovation; $10^{\text {th }}$ Toulouse Conference on the Economics of IP, Software, and the Internet; $3^{\text {rd }}$ Workshop on Marketplace Innovation at Stanford, seminars at North Carolina State University and Elon University, as well as Wendy Bradley, Franco Mariuzzo, and Joel Waldfogel for their comments.
} 


\section{Introduction}

The rise of the "sharing economy" (also known as the "collaborative" or "on-demand" economy), and the success of platforms like AirBnB and Uber have attracted the attention of economists and other academics as well as the popular press (Horton and Zeckhauser, 2016). Einav et al. (2016) define these platforms as peer-to-peer markets and emphasize their role in connecting individuals that can be either sellers, buyers, drivers, or workers, and enabling transactions that would not be possible in traditional markets. ${ }^{1}$ Peer-to-peer markets are increasingly used for transportation, lending, accommodation, home services, deliveries, or task assignments (Sundararajan, 2016). Peer-to-peer platforms have been argued to provide important efficiency gains (Edelman and Geradin, 2015). Specifically, they lower search and transaction costs (e.g., reduce information asymmetries) and allow fuller use of resources (e.g., increase car occupancy). However, our understanding about pricing behavior and market outcomes on peer-to-peer platforms is still limited.

Our paper investigates how price and demand are determined on peer-to-peer markets and whether experience and reputation have the same impact as in traditional markets. We define experience as a seller with a long tenure in the market and reputation as a seller with a lot of good feedback from past buyers. There is a lot of evidence that buyers are willing to pay more for items sold by sellers with good reputation (Bolton et al. 2013; Cabral and Hortacsu, 2010; Jin and Kato, 2006; Melnick and Alm, 2012; Resnick et al., 2006). Sellers also care about their own reputation. Inexperienced sellers use reputation-building strategies, and they tend to charge higher prices as they accumulate

\footnotetext{
${ }^{1}$ Similarly, Rochet and Tirole (2006) and Evans et al. (2011) define these platforms as two-sided markets that bring together two groups of economic agents: sellers and buyers, hosts and guests, or drivers and riders.
} 
experience and ratings (Jolivet et al., 2016). These questions have been extensively studied in the context of marketplaces like eBay or AmazonMarketplace (e.g., Cabral, 2012; Dellarocas, 2003; Tadelis, 2016). It is important to investigate whether experience and reputation can have similar effects on platforms where sharing is a key element of the transaction, most sellers are non-professional, and users' feedback concerns the social experience rather than exclusively the product (Zervas et al., 2015; Fradkin et al., 2014).

In this paper, we focus on intercity ridesharing platforms. With intercity carpooling, drivers and riders share the space within the car together for up to a few hours. Because of these face-to-face interactions, there is a much larger scope for driver and rider characteristics to matter and for behavior to evolve in interesting ways as users gain experience on the platform. Our data come from the leading carpooling platform, BlaBlaCar, which is valued at $\$ 1.5$ billion as of 2015 . BlaBlaCar connects a driver with empty seats to riders to share an intercity trip. The importance of BlaBlaCar has been emphasized by Sundararajan (2016), calling it "the company that dominates [the intercity carsharing] market" and noting that BlaBlaCar moves "as of 2015, more people every day than the US national rail system Amtrak" (Sundararajan, 2016 p. 12).

We use this empirical setting to study the determinants of price setting and demand behavior in order to understand how we should expect these types of peer-to-peer markets to evolve moving forward. The BlaBlaCar setting is uniquely well suited for our study because its price-setting environment is different from other carsharing peer-topeer markets. On platforms like Uber and Lyft, pricing is centralized by the market maker and thus price is the same for any driver offering a given trip at a given moment. In contrast, on BlaBlaCar, pricing is decentralized: drivers set their own price for each 
trip. Further, all drivers on BlaBlaCar are non-professional. This provides rich price variation and interesting price dynamics as drivers gain experience on the platform. ${ }^{2}$

We collected a large data set on the French carsharing market, which is the home market of BlaBlaCar. Our econometric model addresses the endogeneity of the driver's price and, controlling for price, models demand. Our two sets of main results concern a driver's level of experience and demographic characteristics. First, we focus on how drivers' price-setting behavior evolves as they gain experience on the platform. The results suggest that more-experienced drivers set lower prices and sell more seats than less-experienced drivers. The price result is counter to evidence from other offline and online markets, firms with more experience in the market commonly charge higher prices.

Our finding that drivers lower their prices as they gain experience suggests that learning is important in understanding price setting on sharing platforms like BlaBlaCar. Specifically, we find that drivers learn to set lower prices and earn more revenue per trip over time. The effects we document are not being driven by riders' responses to drivers' reputation. These new insights are important relative to the large literature on peer-to-peer markets such as eBay, where demand-side responses to reputation have been the focus (Cabral, 2012). Our results highlight the important role of supply-side changes in pricing behavior as drivers gain experience on the carpooling platform. We conclude that prices and market outcomes on "sharing platforms" such as BlaBlaCar are determined differently than on marketplaces such as eBay.

\footnotetext{
2 BlaBlaCar provides distinct measures for driver's experience and reputation, which allow us to estimate their respective effects. Reputation is about whether the driver can be trusted by riders and is measured by the quantity and quality of feedback left by riders. Experience is about whether the driver has a good understanding of how the carsharing market works, and is measured by a status indicator that takes five values from newcomer to ambassador.
} 
Second, we find the demographic characteristics of a driver have strong predictive power for her price and the demand for her seats. Matching drivers' first/given names to a database of names and their predominant country or region of origin, we classify drivers based on names that are common in our setting of interest, France. Comparing French-sounding names to Arabic-sounding names, drivers with a predominantly French name sell more seats and drivers with a predominantly Arabic name sell fewer seats. An Arabic name is associated with a particularly strong negative effect on demand and reduces driver revenue substantially. Our findings are related to the growing empirical literature on digital discrimination, including studies of AirBnB (Cui et al. 2016, Edelman and Luca, 2014, Edelman, Luca, and Svirsky, 2018, and Kakar et al. 2017), Craigslist (Doléac and Stein, 2013), Uber (Ge et al., 2016), and Prosper.com (Pope and Sydnor, 2011). These studies show evidence of discrimination on both sides of the market (toward suppliers and demanders) and seek to understand the underlying mechanisms (statistical versus taste-based discrimination).

The paper is organized as follows. The next section introduces BlaBlaCar. Section 2 describes our data and Section 3 explains the empirical methodology to analyze market outcomes and address the simultaneity of price setting and demand. Section 4 presents the main econometric results and Section 5 presents revenue results. Section 6 explores the mechanisms that drive our results, while Section 7 concludes. 


\section{The carsharing platform BlaBlaCar}

Founded in France in 2006, BlaBlaCar has become the leading carsharing platform. ${ }^{3}$ BlaBlaCar offers intercity ridesharing services, connecting drivers with empty seats to people who are traveling on the same trip (see Figure 1). Drivers earn money and passengers save on travel expenses (given that the typical trip on BlaBlaCar is cheaper than the corresponding train ticket). As of 2017, BlaBlaCar operates in 22 countries (mainly in Europe, but also in Mexico, India, Russia, and Brazil) and has more than 40 million members. In April 2015, BlaBlaCar acquired the second largest European carsharing company Carpooling.com. BlaBlaCar has not seen the types of regulatory battles faced by carsharing companies like Uber, because BlaBlaCar is considered a notfor-profit ride service. The stated purpose of the money received by drivers is only to share the cost of the trip.

Over 3 million people use BlaBlaCar every month, around $29 \%$ of whom are drivers. The average BlaBlaCar user is 34 years old, with $14 \%$ of drivers and $36 \%$ of passengers being students. Registration on BlaBlaCar is free but passengers pay fees that are about $15 \%$ of the price of the ride paid to the drivers. ${ }^{4}$ Like most other peer-to-peer markets, passengers and drivers are asked to rate each other and write reviews.

For each trip, BlaBlaCar suggests a "recommended price" based on the trip distance and the estimated price of fuel and tolls. ${ }^{5}$ The recommended price does not depend on the

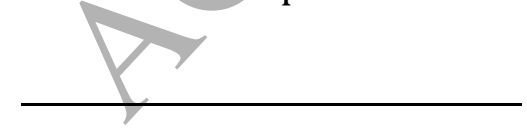

\footnotetext{
${ }^{3}$ The name BlaBlaCar comes from the French word "blabla" that is the English equivalent of blah. Drivers can display their "talking" preference in their profile: Bla if they do not like to talk with passengers, BlaBla if they like to talk a little, and BlaBlaBla if they like to talk a lot. ${ }^{4}$ As of 2015, booking fees and value added tax (VAT) are added to the price that the passenger pays to the driver. The fees earned by BlaBlaCar are composed of a fixed component (€ 0.89) and a variable component ( $9.90 \%$, of the price). A VAT of $20 \%$ is added to these fees. ${ }^{5}$ For instance, in 2015, the recommended price of BlaBlaCar was automatically calculated as follows: .065 € per kilometer and per seat if the driver takes a toll road and .048 € per kilometer and per seat otherwise.
} 
number of seats offered by the driver or the comfort of the car. Then the driver can adjust the price up or down, with the minimum (maximum) price set as 50\% (150\%) of the recommended price. In February 2012, BlaBlaCar introduced a price color classification, where the driver's price appears to potential riders as green if the driver chooses a price that does not exceed the recommended price. Otherwise, the price is orange (up to $125 \%$ of the recommended price) or red (between $125 \%$ and $150 \%$ ).

\section{Data collection}

Data were collected daily from August 2013 to March 2014. BlaBlaCar displays a listing of the most popular French intercity trips on its website, which covered all regions of France including all provincial cities with more than 100,000 inhabitants. From this list, we sampled 40 intercity trips with the highest number of offers in early 2013, which ensures a sufficiently large sample. Among these 40 trips across France, we have trips between provincial cities as well as trip between Paris and a provincial city. The list of trips is available in the appendix, including descriptive statistics (distance, number of observations, and unique drivers for each trip). There are 41 unique cities (33 of more than 100,000 inhabitants and 8 of less than 100,000 inhabitants). The shortest trip is Nimes-Montpellier ( $56 \mathrm{~km})$ and the longest trip is Paris-Marseille $(774 \mathrm{~km})$.

The data collection procedure was automated. For each trip, we collected all offers, resulting in 920,789 observations (i.e., an observation is a trip between two cities, with a departure date and hour, posted by a driver). The data collection script scraped the BlaBlaCar website, resulting in multiple snapshots of each observation (e.g., three days before departure, two days, departure day). We focus on the last observation for each trip. 
The data contain the departure and arrival cities; departure date and hour; driver name; profile (gender, age, etc.); whether the driver's photo is shown; and declared preferences for smoking, pets, and music. ${ }^{6}$ For each trip, we have the number of seats available, the price, and price color (green, orange, or red). If all seats are sold before the departure, the trip continues to show in the search results with the label "Full." This is the case in $54 \%$ of the trips in our data set.

Our empirical analysis requires that we precisely identify drivers. Unfortunately, unlike other online marketplaces, BlaBlaCar does not use unique user IDs as part of its listing interface, an approach that is useful with eBay data, for example. As a result, we need to identify drivers as carefully as possible to identify which listings were offered by the same driver. To do so, we use three variables in our data: name, age, and gender. It is important to note that we have name information on the driver's first/given name as well as the first initial of the driver's last name. Coupled with age and gender, we are able to classify drivers with a high degree of precision. ${ }^{7}$ For these 294,419 individual drivers, they are 36 years old, on average, and around $40 \%$ of listings are by females.

We also collected the ratings and the status of drivers that are publicly observable by riders. When these data were collected, the rating mechanism of BlaBlaCar allowed only a positive or negative rating. In our data set, members' reputation is, therefore,

\footnotetext{
${ }^{6}$ We also attempted to collect data on drivers' preferences for talking (dislikes talking, likes a little talking, or likes a lot of talking). The data for this variable indicate that all drivers set this preference to "a lot," which suggests that our scraping software did not correctly extract this variable. As a result, we cannot control for drivers' talking preference.

${ }^{7}$ To verify our procedure for identifying drivers, we consider data on the comfort rating of the driver's car, whether she allows smoking, whether she allows pets, and whether she requires manual confirmation. When we additionally add these four variables as inputs into our driver identification procedure, only 18 drivers are identified differently between the two approaches. This represents $0.01 \%$ (i.e., one-tenth of one percent) of our drivers. This suggests that we are identifying drivers precisely.
} 
measured by the number and percentage of positive ratings that were received. ${ }^{8}$ The status of the driver is also a key driver characteristic. A driver is classified as newcomer, intermediate, experienced, expert, or ambassador, based on four criteria (\% of profile completion, number of ratings, $\%$ of positive rating, and seniority). To be an ambassador, the driver needs to complete $90 \%$ of her profile (name, gender, preferences, short bio, car comfort, and photo), to receive at least 12 ratings (with more than $90 \%$ of positive ratings) and to have a tenure of at least 12 months. ${ }^{9}$ Table 1 shows the criteria of classification for status. Controlling for reputation, a driver's fivelevel status measures her experience level.

\section{[Insert Table 1]}

We also collected the comfort of the driver's car on a 4-level scale, where higher values indicate a more luxurious vehicle. Comfort is self-classified by the driver (basic, normal, comfortable, or luxury) and $11.36 \%$ of drivers do not disclose any comfort level. However, we have no information on the make or model of the car (or fuel efficiency).

Table 2 presents summary statistics. Panel A presents our explanatory variables, including each driver only once, while Panel B summarizes the outcomes of interest for the entire sample at the trip level (price and quantity). The variables in Table 2 are those described earlier in this section.

\section{[Insert Table 2]}

Regarding drivers (panel A), the number of ratings received is 8.4 on average, while driver status is 2.7 and car class is 2.3 on average. Using a database of names and associated country/region of origin, we classify drivers by the most prominent region of

\footnotetext{
${ }^{8}$ As of 2015, BlaBlaCar's rating system has expanded to include a five point scale.

${ }^{9}$ Most of profile information is required at the registration, but some remains optional like displaying a photo or linking her profile to her Facebook account.
} 
origin of their first/given name. ${ }^{10}$ Our approach classifies $67 \%$ of drivers as having a French-sounding name (e.g., Guillaume, Pierre, and Sophie), 5\% as having an Arabic- or Muslim-sounding name (e.g., Ahmed, Mariama, and Youssef), and the remaining 28\% as having a name that is neither predominantly French nor Arabic (e.g., Kim, Mickael, and Tony).

Further, drivers include a picture with their profile in $39 \%$ of cases. $56 \%$ of drivers indicate that they play music during the trip, $9 \%$ allow pets, and $7 \%$ allow smoking. Finally, $26 \%$ of drivers offer roundtrip travel, while $12 \%$ of drivers allow a seat to be sold only after manually confirming the sale. The alternative to manual confirmation is that the passenger's trip is confirmed instantly, which is similar to Instant Book on AirBnB.

Regarding trips (panel B), the price per seat is measured in integer euros. In our data set, the average price for a trip is around 13 euros, with substantial variation (standard deviation of 9.4 euros). Next, relative price is shown, which is the driver's price minus BlaBlaCar's recommended price. The average price is 2.8 euros lower than the recommended price. This implies that the recommended price is not serving as a de facto market price. To provide further evidence on this point, Appendix Table A2 tabulates drivers' relative prices. The recommended price is not the modal price; the most common prices are one and two euros lower than the recommended price. These results suggest that pricing on BlaBlaCar is decentralized, as we have argued. When we group drivers according to their status level, ranging from one to five for newcomer, intermediate,

\footnotetext{
${ }^{10}$ We collected data on names origin from three web sources: www.insee.fr (the French National Institute of Statistics and Economic Studies) and two well-known French websites: http://www.prenoms.com and http://www.signification-prenom.net. The resulting database contained over 69,000 first/given names along with their country of origin, which was crosschecked across these three websites for accuracy.
} 
experienced, expert, or ambassador, we find that prices fall as drivers gain higher status levels.

Table 2 also displays the two quantity measures that we use in our regressions: the fraction of listed seats that sold and the all seats sold dummy variable. To obtain the first measure, we rely on the panel nature of our data with repeated listings for a given driver. The data-extraction software used to gather data regularly visited hundreds of thousands of BlaBlaCar listing pages but instantaneous data collection is infeasible. As a result, the data occasionally contain a number of seats available that already reflects a lower quantity than the true quantity supplied. That is, when the software scraped a given listing's page, the number of seats available may already be lower by one seat if a rider purchased a seat before the page was first scraped. While the data collection may miss a seat sold for a driver on a given listing it is unlikely to systematically miss seats sold on all listings that a driver ever offers. As such, we construct a variable that is equal to the maximum number of seats offered ever observed by the driver across all of her listings (seats in car). ${ }^{11}$ Then the fraction of seats sold is equal to the number of seats sold divided by the maximum number of seats offered by the driver (as defined above). The proportion of seats that sold for a listing varies between zero (all seats are unsold) and one (all seats are sold); the average is 0.62 .

The second measure is more straightforward: all seats sold is a dummy variable that equals one when the number of seats available equals zero at the close of the listing. Importantly, the all seats sold dummy is robust to our approach for measuring the number of seats available in the car. While we imperfectly observe the number of seats initially offered, we perfectly observe the number of seats still available for each listing,

\footnotetext{
${ }^{11}$ We do not have data on the make and model of the car and instead have only a measure of the comfort level of the car.
} 
irrespective of how soon or how often the data-extraction software gathered data on a listing. If zero seats are available when the listing closes, then all seats sold, by definition. The two quantity sold measures provide similar results in what follows, providing support for our approach for defining quantity sold. ${ }^{12}$

\section{Econometric Model}

To understand the functioning of the BlaBlaCar carsharing platform, we perform a regression analysis to explain the prices charged and quantities sold by drivers. We also consider revenue but defer discussion of our revenue analysis until Section 5 . We use data listed on BlaBlaCar starting from August 2013 until March 2014. The resulting data set contains 920,789 listings from 294,419 distinct drivers.

The outcomes of interest are price and quantity sold. We present an instrumental variables regression analysis, where price is considered an endogenous variable that affects quantity sold. Our econometric model is a two-stage least-squares fixed-effects panel-data regression on both price and quantity, with trip fixed effects. A trip is defined as a departure city-arrival city pair. Including trip fixed effects allows us to control for the general characteristics of the trip, then look separately at specific factors that affect drivers' prices and riders' demand.

For price, the model is a linear regression. By using trip fixed effects, our price measure is analyzed in a comparable way across trips (i.e., trip fixed effects control for the

\footnotetext{
12 We could alternatively use the number of seats sold in our demand regressions. However, doing so is problematic because it treats different sized cars (small cars versus large sports utility vehicles) differently, which could create endogeneity issues if different types of drivers have different sized cars in ways that are unobservable and related to our explanatory variables of interest (e.g., age or gender).
} 
average price across all listings of the trip). For the fraction of seats sold and the all seats sold dummy variable, we again use linear regression. Our use of linear models is consistent with the approach advocated by Angrist and Pischke (2008). In all specifications, continuous explanatory variables are included in quadratic form, with the results shown as the average marginal effects. Allowing the explanatory variables to have nonlinear effects is more flexible and several variables should be expected to have a nonlinear effect (e.g., price on demand).

To control for price endogeneity, we construct instruments from the trip-level panel nature of our data. Specifically, we link drivers who offer a given trip to other trips offered by the same driver to infer the average characteristics of "trips other than the trip in question." For example, suppose a driver is only ever observed offering trips from Lyon to Grenoble and from Lyon to Paris. If Lyon to Grenoble is the trip in question, then Lyon to Paris trips refer to the "trips other than the trip in question." We instrument for the price of a seat by using the average price charged by the same driver on "all trips other than the trip in question". For the drivers who only ever offer one trip, there are no such trips. We refer to these drivers as single-trip drivers and, for these drivers, the average-other-price instrument equals zero. This instrument is essentially a combination of two distinct characteristics of drivers. First, does the driver offer trips between a pair of cities that is different from the pair of cities in question? This factor determines whether the instrument is positive. Second, if yes, did the driver set prices that were high or low, on average, on those other trips? This factor determines the continuous variation in the instrument. Our instrument essentially combines a dummy variable for whether the driver offers trips other than the trip in question and, if so, a continuous variable measuring average price on those trips. 
The intuition behind the "average-other-price instrument" is that a combination of observed and unobserved characteristics of the driver affects the price she sets. Because the econometrician has access to all observed characteristics, the variation in price that is affected by the unobserved characteristics should be highly correlated across the driver's listings on the trip in question and her listings on trips other than the trip in question. ${ }^{13}$

Further, we believe that the average-other-price instrument is plausibly exogenous because it reflects underlying factors about the driver that should not affect demand except through the price set on the listing in question. It is useful that we have a large number of alternative trips because constructing the average price the driver set for other listings on the same trip is likely to itself be endogenous; such an average-sameprice instrument is problematic because potential ríders might observe a given driver offering a given trip across multiple listings of the trip (with different departure dates). By using the average price on trips other than the trip in question, we greatly reduce the possibility that riders have any sense of where the driver falls in the price distribution for other trips. In Table 2, the average-other-price variable averages around 11 euros, while just over half of the drivers in our sample only ever offer one trip. The averageother-price instrument equals zero for these drivers, which represent $21.1 \%$ of the total number of observations.

\footnotetext{
${ }^{13}$ In Appendix B, we discuss a set of robustness checks using two sets of alternative instruments. The first set of alternative instruments use the one week lag of characteristics of other drivers on the same trip in the prior week. These instruments are exogenous under the argument that past trips reflect underlying supply characteristics that affect contemporaneous price in exogenous ways conditional on observables. The second set of alternative instruments use characteristics of other drivers on the driver's modal trip (other than the trip in question) during the same week. These instruments are exogenous under the argument that drivers' pricing behavior is affected by their competitive interactions in the other markets where they drive. The results are robust across these very different IVs.
} 
Our instrument is in the spirit of commonly used instruments in the Industrial Organization literature, which are often called BLP instruments, following Berry, Levinsohn, and Pakes (1995). This cross-market feature of our instrument is shared with the empirical Industrial Organization papers using these type of BLP instruments.

4. Empirical Results

Using the average-other-price instrument, we conduct an instrumental variables panel regression analysis with trip-fixed effects, where the first stage asks what factors affect the driver's price and the second stage asks what factors affect the quantity sold, controlling for the endogeneity of the price in its determination of quantity sold. As explained earlier, price is measured in integer euros and quantity sold is measured in two ways: the fraction of seats sold and a dummy variable that equals one if all seats sold.

Table 3 presents the determinants of the drivers' price with and without the averageother-price instrument. Column (2) with the instrument serves as the first-stage of our IV regression analysis. The use of trip fixed effects implies that the variation we exploit is the driver's price relative to the average price on the trip. This controls for timeinvariant trip characteristics such as distance. We also control for departure time of day, day of week, and a time trend (see appendix Table A3). ${ }^{14}$

\footnotetext{
${ }^{14}$ We include an analysis with driver fixed effects in Table 6 and confirm the main results. We prefer trip fixed effects for two reasons: (1) within-driver results exploit different variation than our main analysis that exploits between-driver variation and (2) within-driver analyses require us to restrict the sample to drivers with enough trips and might limit our ability to learn something about very new drivers or drivers who offered a few trips and exited the platform.
} 
First, we discuss the validity of our instrument, then we discuss the results for price along with the results for demand. In Column (2), the average-other-price instrument (average price on trips other than the trip in question) is highly statistically significant. Increasing the price on other trips by one euro is associated with a one cent higher price. The size of this effect suggests that the latent characteristics of the driver that introduce a correlation between prices on different trips are statistically meaningful but quantitatively small. This implies that trip-specific factors (e.g., the recommended price) are more important than driver-specific factors in pricing but driver-specific factors are sufficiently important to ensure the strength of the average-other-price instrument.

\section{[Insert Table 3]}

The first-stage F statistic that is shown in Table 3 equals 1939.0, which is very large and considerably above the rule-of-thumb of 10 in order to mitigate concerns about weak instruments (Angrist and Pischke 2008). Further, we measure the strength of both components of the variation in the average-other-price instrument: first, the zero/nonzero variation in the instrument of whether the driver offers trips other than the trip in question and, second, the continuous variation in the instrument of the average price on those trips.

To measure the strength in the zero/non-zero variation, we rerun the first-stage weak instrument test with an instrument that equals one if the driver only ever offered a single trip. The first-stage F statistic in this case equals 219.3. We also rerun the firststage weak instrument test for only multiple-trip drivers to ask whether the continuous variation in the instrument is strongly associated with price. The statistic in this case equals 1886.6. Thus, most of the strength of the instrument comes from the continuous variation but both sources of variation are sufficiently strong to support the use of the 
average-other-price instrument as a strong predictor of prices. ${ }^{15}$ In Appendix B, we discuss a set of robustness checks using two sets of alternative instruments: the average fraction of orange or red prices (above the recommended price) for the prices set by other drivers on the same trip in the prior week, and the average characteristics of other drivers on the driver's modal trip (other than the trip in question) during the same week. The results are very robust, as can be seen by comparing Table 4 to Tables B1 and B2.

To discuss the results, we discuss the determinants of price from Table 3 and of quantity sold from Table 4 together. In Table 4, Columns (1) and (3) present OLS demand regressions for the fraction of seats sold and for the all seats sold dummy respectively, while Columns (2) and (4) present IV demand regressions using the average-other-price instrument to isolate the exogenous variation in the driver's price.

The results for these two measures of demand are very similar, leading us to only discuss Columns (1) and (2). Having a higher price is associated with fewer seats sold, but the effect is much larger when we instrument for price. ${ }^{16}$ Controlling for price endogeneity, fraction sold decreases by around 8 percentage points for each one euro higher price, relative to a mean fraction sold of $62 \%$.

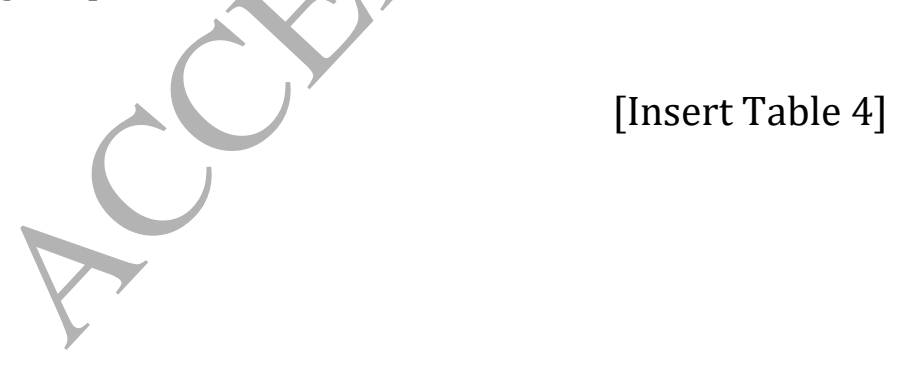

\footnotetext{
${ }^{15}$ In Table A5, we rerun the demand regressions with only multiple-trip drivers. Comparing the main results in Table 4 to this robustness check in Table A5, we see that the results are extremely similar.

${ }^{16}$ The increase in the (absolute value of the) price elasticity in the IV results is consistent with heterogeneity in pricing behavior that is correlated with the error term in the demand regression, generating attenuation bias in the OLS result.
} 
We have two sets of main results from Tables 3 and 4: driver experience/reputation and driver demographics. We discuss these main results, then the remaining findings. ${ }^{17}$

\section{Driver Experience/Reputation}

The richness of our BlaBlaCar data allows us to control for driver reputation, which has been the focus on other studies of online markets, separately from driver experience. Reputation is measured in terms of quantity (number of feedback ratings received) and quality (percentage of positive ratings relative to all ratings received). Holding reputation constant, driver status measures a driver's experience level on the BlaBlaCar platform. On its website, BlaBlaCar defines this five-tier status as the level of driver's experience. ${ }^{18}$

The results suggest that more-experienced drivers set lower prices: drivers with the highest status (ambassador) set prices that are 44 cents lower than drivers with the lowest status (newcomer). This is a moderate effect size relative to a mean price of 13.4 euros; however, this effect represents one of the larger effects of any explanatory variable in Table 3. In contrast,driver reputation has a weak relationship with price. More feedback of a driver has an effect that is essentially zero: moving from 0 ratings to 13.1 (the mean) is predicted to decrease price by 0.5 cents (half a cent). The quality of a driver's reputation (better feedback) has a positive effect that is also small: if a driver's reputation increases from $90 \%$ to $100 \%$ positive, price is predicted to increase by 5.2 cents

\footnotetext{
${ }^{17}$ Note that the Wu-Hausman test of endogeneity of price in the demand estimation provides an $F$ statistic of 1543.2 (p-value $=0.00$ ), which rejects the null that price is exogenous and supports our use of an instrumental variables analysis.

${ }^{18}$ We do not directly observe drivers' registration date on the platform or other precise measures of the activity of drivers on BlaBlaCar. However, the labels associated with driver status unambiguously refers drivers' experience on the carsharing platform (newcomer, intermediate, experienced, expert, ambassador) and the highest levels can be reached only if a driver is regularly posting offers.
} 
Turning to Table 4, drivers with more experience sell more seats, controlling for price: ambassadors (highest status level) have a fraction sold that is 5.2 percentage points higher than newcomers (lowest status level). For drivers in the middle status levels (intermediate, experienced, and expert), the effect is around one percentage point but there is a discrete jump in demand for drivers at the highest experience level. Concerning drivers' reputation, more and better feedback is associated with higher quantity demanded: moving from 0 ratings to 13.1 (the mean) is predicted to increase the fraction of seats sold by 0.2 percentage points, while moving from $90 \%$ positive to $100 \%$ positive is predicted to increase the fraction of seats sold by 2.0 percentage points. As for price, feedback effects remain very small nonetheless.

Overall, we conclude that more-experienced (higher status) drivers set lower prices than less-experienced drivers, with a moderate effect size. Further, more-experienced drivers sell more seats, with a particularly strong effect associated with moving to the highest experience level (ambassador). ${ }^{19}$ /Drivers with better reputations (in terms of quantity and quality of ratings) sell also more seats and set higher prices. However, these effects are much smaller than the effect of driver experience. ${ }^{20}$ Intuition from offline markets suggest that more-established firms typically charge higher prices. Evidence from eBay and other marketplaces shows that seller with more experience are able to sell for higher prices (Cabral and Hortacsu, 2010; Jolivet et al., 2016; Resnick and Zeckhauser, 2002; Resnick et al. 2006). In contrast, we interpret our finding as

\footnotetext{
${ }^{19}$ Table A4 presents a step-by-step set of regressions that look at the relationship between a driver's level of experience and her price, sequentially adding additional regressors. The main result that more-experienced drivers set lower prices holds in all specifications.

${ }^{20}$ In unreported results, we rerun the price analysis for the most-experienced drivers and for all other drivers separately. The results suggest that more reputation quantity is associated with a 26.9 cent price decrease when moving to the mean of 13.1 ratings for the less-experienced drivers (lower than ambassador status) but there is no additional effect of reputation quantity once a driver reaches ambassador status.
} 
suggestive that new drivers on BlaBlaCar are using a different decision-making process when setting prices than that of experienced drivers. Section 5 provides a discussion of potential mechanisms for the role of experience on pricing behavior, where we separately test for learning and selection effects.

Finally, we present a robustness check of the experience result separately for each trip, using a nonparametric trend test of whether prices fall as driver experience increases. Across all 40 trips, we find that there is a statistically significant decrease in prices as driver experience increases for 37 of 40 trips (exceptions with a statistically significant increase: Lens-Paris, Nice-Toulon, and Rouen-Paris). We notice nothing systematic about these three exceptions (e.g., Lens-Paris has a positive price-experience relationship while Lille-Paris has a negative price-experience relationship, but the two trips are similar in most regards). ${ }^{21}$

\section{Driver Demographics}

Our next set of main results concern demographic characteristics of the driver: name origin, gender, and age. As discussed earlier, a driver's first/given name may signal her origin or ethnicity and we match names to predominant country of origin to classify drivers as having a French-sounding name (67\% of drivers), an Arabic-sounding name (5\%), or a name that is neither predominantly French nor Arabic $(28 \%)$.

Drivers with a French name set prices that are 3 euro cents higher than the omitted group of all other names. In contrast, drivers with an Arabic name set prices that are around 21 cents lower. Controlling for price, drivers with a French name sell more seats, while drivers with an Arabic name sell fewer seats (fraction of seats sold increases by six percentage points and decreases by seven percentage points, respectively). The

\footnotetext{
${ }^{21}$ The distance between Lille and Lens is only 36 kilometers.
} 
effect size of having an Arabic-sounding name on BlaBlaCar is similar to that found in work on AirBnB for black, Asian, and Hispanic hosts (Edelman and Luca 2014, Kakar et al., 2017) or on Craigslist for black sellers (Doléac and Stein, 2013). Our results suggest either discrimination or unobserved heterogeneity that is correlated with demographics. However, given our rich set of controls, we believe that there is limited scope for unobserved heterogeneity in explaining why we observe such differences because we control for essentially all of the characteristics that are observed by potential riders. Nevertheless, we use the term discrimination cautiously without conclusive evidence.

Next, we ask whether the driver name effect continues to matter when considering only the most experienced drivers (ambassador status). We find that the negative effect of having an Arabic-sounding name on seats sold is smaller among the most experienced drivers (6.9 percentage points less demand for Arabic names than French names) relative to result among all drivers (13.6 percentage points less demand for Arabic names than French names).22

As with the experience result, we measure the effect of an Arabic name separately for each trip, using a $\mathrm{t}$-test of whether Arabic drivers have lower average sales probability than other drivers. Across all 40 trips, we find that there is a statistically significantly lower average sale probability for Arabic drivers for 35 of 40 trips (exception with a statistically significantly higher probability: Amiens-Beauvais, exceptions with no statistically significant difference: Besancon-Dijon, Dijon-Besancon, Metz-Nancy, and

\footnotetext{
${ }^{22}$ The effect of having an Arabic-sounding name is expressed relative to having a Frenchsounding name, so the effects reported are the sum of the coefficients for French and Arabic. The full set of results from the robustness checks discussed in this section are available from the authors upon request.
} 
Saint Etienne-Clermont). The presumption of digital discrimination for drivers with a predominantly Arabic name is therefore quite robust. ${ }^{23}$

Regarding gender effects, female drivers set prices that are 12 cents higher than male drivers, on average. Controlling for price, the fraction of seats sold is three percentage points higher for female drivers than for males. The higher demand for rides listed by female drivers may suggest that both female and male riders prefer a female driver, but we do not have data on rider characteristics to test this hypothesis.

Finally, older drivers set higher prices and, controlling for price, sell no fewer seats, on average. Recall that age (along with the other continuous explanatory variables) is included in quadratic form, where the results shown in Table 3 are the average marginal effects. We look for nonlinearities in the effect of age in the Appendix (Figures A1 and A2). There is not much curvature for the effect of an additional year of age on price, but there is a nonlinear effect of age on quantity demanded: among younger drivers, an additional year of age is associated with more sales, while, among older drivers (late 30s or older), an additional year of age is associated with fewer sales.

\section{Other Results}

Beyond these main results, several other interesting patterns emerge. Class measures the car's comfort level, where zero represents no indication of the class, relative to values between one (basic comfort) to four (luxurious). The results suggest that, for drivers who do not disclose a class, prices are set as if the car is of average comfort (similar to a class of three). However, controlling for price, undisclosed quality cars are

\footnotetext{
${ }^{23}$ We also compare Arabic and French names among only those drivers whose car is of the highest comfort level to see if the results can be explained by rider perceiving that a driver with a non-French name might drive a less luxurious car. Among these drivers, Arabic drivers also sell fewer seats than non-Arabic drivers and the effect size is similar to the main results.
} 
associated with fewer seats sold, where these cars sell one percentage point fewer seats than cars of the lowest disclosed comfort level. The demand result is consistent with the unraveling result economists often predict under voluntary quality disclosure. We note that there is a large effect of manual confirmation on price and demand, suggesting a strong preference of riders not to be required to request confirmation of the ride. In Appendix C, we analyze this choice more fully and find that the use of manual confirmation reflects a lack of experience with the platform.

\section{Empirical Analysis of Revenue}

We have thus far focused on the determinants of price and demand; now we present results on revenue. Revenue is equal to the number of seats sold times the price. The disadvantage of an analysis of revenue is that it does not allow us to disentangle the determinants of supply (which we approach with our price analysis in Table 3) from the determinants of demand (Table 4). However, revenue is the cleanest way to measure the magnitude of the effects that we have documented. We seek to measure the size of the effects of driver demographics and the cumulative effect of driver experience (given that more-experienced drivers set lower prices but sell more seats). Our regression model for revenue is a Tobit model. Table 5 presents these results.

First note in Table 5 that we added the maximum number of seats in the driver's car as a covariate, which did not appear in our earlier analyses. The disadvantage of including seats in car is that the size of a driver's car might interact with other driver characteristics of interest in complex ways. As a result, we did not include seats in car in the price or demand regressions. However, seats in car are a strong determinant of 
revenue because more seats in the car necessarily imply more seats can be sold. Logically, we find this holds in the results, where one additional seat in the car is associated with seven euros more in revenue.

More importantly, we find that more-experienced drivers earn more revenue per trip, with a meaningful effect of moving to the highest status level. Drivers of intermediate status levels earn around 80 euro cents more than those with the least experience, while drivers with the most experience (ambassador) earn nearly two euros more in revenue. Further, drivers with an Arabic-sounding name earn 1.1 euros less than the omitted group (drivers with neither French nor Arabic-sounding names), while drivers with a French-sounding name earn 7.4 euros more than the omitted group. Comparing French and Arabic-sounding names, Arabic drivers earn 8.6 euros less in revenue. This is an extremely large effect relative to a mean revenue of 14.8 (58.4\% reduction in revenue), which gives an estimate of the cost of being discriminated against on a carsharing platform.

Given our emphasis on the price and demand results over the revenue results, we do not present an extended discussion of the remaining results in Table 5. Not surprisingly, most of these other results agree with those from Tables 3 and $4 .^{24}$

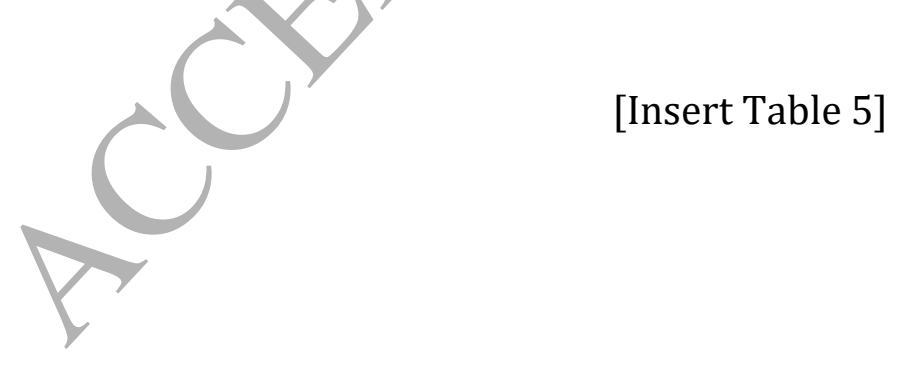

\footnotetext{
${ }^{24}$ There is one odd result for revenue relative to the earlier tables: females earn around 50 euro cents in revenue less than males. The explanation is that female drivers drive smaller cars than male drivers (seats in car for females is 0.4 seats lower). We rerun the revenue analysis of Table 5 where we interact seats in car with gender and find that a female driver with a given number of seats in her car earns more revenue than a male driver with the same number of seats. For example, a female with three seats in her car earns one euro more in revenue than a male driver with three seats (16.79 versus 15.76).
} 


\section{Testing Explanations Based on Learning versus Selection}

Two separate mechanisms could account for the negative relationship we document between a driver's experience and her price. A first explanation involves learning: drivers learn to lower their prices as they gain experience. A second explanation involves a selection effect: drivers who offer low prices on sharing platforms are more likely to gain a lot of experience. To provide evidence on the relative importance of these two explanations, we first use within-driver price dynamics to test for a learning effect, while accounting for selection. Then, we test for the degree to which selection exists.

Table 6 explores the determinants of price-setting behavior additionally including driver fixed effects, which controls for the difference in price levels across drivers and exploits variation in price changes for a given driver over time. The question of interest is whether a driver sets lower prices when she has more experience relative to the prices she set when she had less experience.

\section{[Insert Table 6]}

Table 6 presents the results for all drivers with at least eleven listings, which includes 12,989 individual drivers and 276,178 observations. ${ }^{25}$ In the econometric specification, the included covariates are driver feedback quantity and quality, driver experience, departure characteristics, trip fixed effects, and driver fixed effects (i.e., all time-varying covariates plus fixed effects).

Table 6 confirms that drivers lower their prices as they gain experience, thus supporting a learning explanation for our earlier results. Specifically, controlling for changes in a

\footnotetext{
${ }^{25}$ Eleven listings is chosen based on the next set of analyses, which splits a driver's tenure into early (first ten listings) and late (listings eleven and later).
} 
driver's feedback, moving to a higher level of experience is associated with lower prices. Our interpretation is that drivers are induced to set lower prices as they gain experience, because they learn about profit maximization over time (e.g., learn that lower prices increase demand enough to raise profits) and about utility maximization over time (e.g., learn that they enjoy the platform and the socialization it provides). To conclude our analysis of a learning explanation versus selection, we test the degree to which drivers with a lot of experience appear to be a selected sample.

To do so, we split each driver's tenure on BlaBlaCar during our sample period into two periods, a driver's first ten listings versus all later listings. Then, we summarize the driver's early-tenure prices to categorize drivers into four quartiles based on their prices during the first ten listings. To deal with price differences across trips and other factors that affect prices, we use relative prices (i.e., the driver's price minus the recommended price) to calculate the driver's average relative price during the early part of her tenure. Drivers are classified into four early-tenure price categories based on the four quartiles of the average relative prices. We only include drivers who we initially observe as a newcomer (status of one); this ensures that the pricing behavior we characterize as early in a driver's tenure is in fact when she was (literally) a newcomer to the platform. We further only include drivers with at least eleven listings so that we can observe the first ten listings.

The results in Table 7 suggest that there is not a monotonic pattern in a driver's number of late-tenure listings as a function of her early-tenure prices: the highest-priced drivers (category four) have 11.34 late-tenure listings, on average, while the lowest-priced drivers (category one) have 10.99 late-tenure listings. Further, drivers whose relative prices were in the third quartile of the price distribution have the most late-tenure 
listings (11.79). This nonmonotonic pattern is inconsistent with the selection explanation (which says that the most-experienced drivers are a selected sample of drivers who have consistently set low prices since their first listing on the platform). These results suggest that selection is not driving our results. Along with the results in Table 6, we conclude that drivers learn to lower prices as they gain more experience on the platform.

[Insert Table 7]

This evidence suggests that learning, not selection, drives our main result that BlaBlaCar drivers with more experience set lower prices. Our final exercise is to document the types of pricing strategies that drivers use over time and how they learn from their initial BlaBlaCar experiences. This illustrates which types of drivers are lowering their prices and to what extent. The results are shown in Table 8. We again categorize drivers based on the first ten listings, here based on the fraction of seats sold on average during the early-tenure trips. We are interested in which drivers lower their prices more or less as a function of how many seats they sold on average early in their tenure. The prices shown in Table 8 are the predicted relative price ${ }^{26}$ charged by drivers across their tenure on the platform, using the regression model from Table 3. Column (3) shows the initial price, which is the average relative price measured for drivers' first observed trip; Column (4) shows the later price, which is the average relative price measured for drivers' who have had the average number of trips (17.2). Finally, Column (5) shows the price change from initial price to later price along with the standard error of the difference.

\footnotetext{
${ }^{26}$ Using predicted relative price allows us to control for other observed factors that affect price and look at ceteris paribus effects of early trips on late trips.
} 
[Insert Table 8]

Table 8 shows that the "learning to lower prices" result is driven by drivers who sold none of their seats early in their tenure on the platform. The effect is monotonic in firsthalf sales rate: 44 cent reduction for drivers who sold no seats initially, 12 cent reduction for those who sold less than half but some seats, and 4 cent reduction for those who sold more than half but not all seats. For the drivers who sold all seats in all early listings, the learning effect is a price increase of 45 cents. These results intuitively reflect that the pricing dynamics we observe are explained by drivers who appear to have been pricing too high early in their tenure. The result is also consistent with driver who initially experienced no socialization benefits from the platform (drove in an otherwise empty car) learning to price in ways to attract riders.

\section{Discussion and Conclusion}

Despite the increasing importance of carsharing, these platforms have received only limited econometric analysis. Our paper studies the largest intercity carsharing platform in the world to understand the functioning of these type of peer-to-peer markets. We are particularly interested in assessing how much of our understanding from the literature on other types of peer-to-peer markets such as eBay carries over to the "new sharing economy" such as BlaBlaCar. The peer-to-peer markets in the latter category allow both online and offline interactions between users. As a result, pricesetting and demand behavior are likely to present novel insights relative to the large literature that studies these questions using data from marketplaces such as eBay.

The main advantage of using BlaBlaCar to study pricing and market outcomes is that prices are set by individual drivers, relative to a "recommended price" that is suggested 
by BlaBlaCar. In contrast, on other peer-to-peer markets in the transportation sector such as Uber and Lyft, price setting is centralized and thus any driver offering a given trip at a given moment has the same price. Our focus is on experience in pricing setting, thus decentralized pricing is important to understand strategic behavior.

In an econometric model that explicitly accounts for price endogeneity, we find that more-experienced drivers set lower prices and, controlling for price, sell more seats. We interpret this as evidence that prices and market outcomes on "sharing platforms" such as BlaBlaCar are determined differently than on electronic marketplaces such as eBay. Given that we find that more-experienced drivers earn more revenue, a leading explanation is that more-experienced drivers are better at revenue maximization. This is in line with results from AirBnB in Li, Moreno, and Zhang (2016), who show that experienced (professional) hosts are better than less experienced (non-professional) hosts at adjusting their price in response to demand fluctuations. Although all drivers on BlaBlaCar are non-professionals, they do not all have the same experience level, and we find evidence of learning to maximize revenues. This suggests that BlaBlaCar should assist inexperienced drivers, for example, using "heat maps" like displayed by Uber to their drivers to indicate the areas where they are more likely to earn higher revenues. BlaBlaCar could also recommend lower prices to newcomers than to experienced drivers.

Further, we find that driver demographics matter in interesting ways: our quantitatively strongest demographic predictor of demand is whether the driver has an Arabic name, which robustly reduces the driver's demand and revenue by a substantial amount. Our results concerning the outcomes of drivers with Arabic names suggests a role of policymakers in working with platforms such as BlaBlaCar to lessen the harm 
associated with (implicit or explicit) bias. Several suggestions along these lines are possible, all while keeping in mind the central role of trust among users of sharing platforms such as BlaBlaCar. First, drivers could be identified by user IDs (as done on eBay for example) without pictures, which would remove the identifiers that might reveal characteristics that might be subject to differential treatment. Second, BlaBlaCar could encourage or require automatic confirmation (which is similar to Instant Book on AirBnB); in conjunction with the removal of names and pictures, this instantaneous booking of trips removes the potential for screening on the part of drivers who might have preferences over certain characteristics of riders.

The rich nature of our BlaBlaCar data allows us to present a detailed analysis of market outcomes in an important type of peer-to-peer market. However, as usual with data from online markets, there are some features of the data that limit the questions we can ask. First, we do not observe information about the riders who are buying seats. Thus, we cannot measure the degree of homophily or social links between drivers and their passengers. Second, we have only a binary scale for ratings (positive or negative). Since the time of our data collection, BlaBlaCar has adopted a five-level reputation measure, which would be useful to verify our findings on the effects of experience on price and quantity demanded. Moreover, as the platform has matured, it will be interesting to analyze how the role of driver experience and demographics has evolved. 


\section{References}

Angrist, J. D., Pischke, J. S. (2008). Mostly Harmless Econometrics: An Empiricist's Companion. Princeton University Press.

Berry, S., Levinsohn, J., Pakes, A. (1995). Automobile prices in market equilibrium. Econometrica, 841-890.

Bolton, G., Greiner, B., Ockenfels, A., (2013). Engineering Trust: Reciprocity in the Production of Reputation Information, Management Science, 59, 2, 265-285.

Cabral, L., Hortaçsu, A. (2010). The Dynamics of Seller Reputation: Evidence from eBay, The Journal of Industrial Economics, 58: 54-78.

Cabral, L. (2012). Reputation on the Internet, in Martin Peitz and Joel Waldfogel (Eds), The Oxford Handbook of the Digital Economy, Chapter 13.

Cui, R., Li, J., Zhang, D., (2016) Discrimination with Incomplete Information in the Sharing Economy: Evidence from Field Experiments on Airbnb. Available at SSRN: https://ssrn.com/abstract=2882982

Dellarocas, C., (2003). The Digitization of Word-of-Mouth: Promise and Challenges of Online Reputation Mechanisms, Management Science 49, p. 1407-1424.

Doleac, J. L., Stein, L. C. (2013), The Visible Hand: Race and Online Market Outcomes. Economic Journal, 123: p. 469-F492.

Edelman, B., Luca, M. (2014). Digital Discrimination: The Case of airbnb.com, Harvard Business School, Working Paper 14-054.

Edelman, B., Luca, M., Svirsky D, (2018). Racial Discrimination in the Sharing Economy: Evidence from a Field Experiment, American Economic Journal: Applied Economics.

Edelman, B., Geradin D. (2015). Efficiencies and Regulatory Shortcuts: How should we regulate companies like AirBnB and Uber? Harvard Business School Working Paper.

Einav L., Farronato C., Levin J. (2016). Peer-to-Peer Markets, Annual Review of Economics, Vol. 8:615-635.

Evans, D. S., Schmalensee, R., Noel, M. D., Chang, H. H., \& Garcia-Swartz, D. D. (2011). Platform economics: Essays on multi-sided businesses. Competition Policy International.

Fradkin, A., Grewal, E., Holtz, D., Pearson, M. (2014). Reporting Bias and Reciprocity in Online Reviews: Evidence from Field Experiments on AirBnB. Working paper. Available at http://andreyfradkin.com/assets/long paper.pdf

Ge, Y., Knittel, C., MacKenzie, D., Zoepf, S. (2016). Racial and Gender Discrimination in Transportation Network Companies NBER Working Paper No. 22776 
Horton, J. J., Zeckhauser, R. J. (2016). Owning, Using and Renting: Some Simple Economics of the" Sharing Economy. National Bureau of Economic Research Working Paper No. 22029.

Jin, G., Kato A. (2006). Price, Quality, and Reputation: Evidence from an Online Field Experiment. Rand Journal of Economics 37, p. 983-1004.

Jolivet, G., Jullien, B., Postel-Vinay, F. (2016). Reputation and Prices on the e-market: Evidence from a Major French Platform. International Journal of Industrial Organization $45,59-75$.

Kakar, V., Voelz, J., Wu, J., Franco, J. (2017). The Visible Host: Does race guide Airbnb rental rates in San Francisco?, Journal of Housing Economics, forthcoming.

Li, J., Moreno, A., Zhang, D. (2016). Pros vs Joes: Agent Pricing Behavior in the Sharing Economy. Ross School of Business Paper No. 1298. Available at https://ssrn.com/abstract=2708279

Melnik, M. I. and Alm, J. (2002), Does a Seller's eCommerce Reputation Matter? Evidence from eBay Auctions. The Journal of Industrial Economics, 50: 337-349.

Pope, D. G., \& Sydnor, J. R. (2011). What's in a Picture? Evidence of Discrimination from Prosper.com. Journal of Human Resources, 46(1), 53-92.

Resnick, P., Zeckhauser, R. (2002). Trust Among Strangers in Internet Transactions: Empirical Analysis of eBay's Reputation System, M. Baye (Ed), Advances in Applied Microeconomics (Volume 11), Elsevier Science, Amsterdam, p. 667-719.

Resnick, P., Zeckhauser, R., Swanson, J., Lockwood, K. (2006). The Value of Reputation on eBay: a controlled experiment, Experimental Economics 9, p. 79-101.

Rochet, J.-C., Tirole, J(2006), Two-Sided Markets: A Progress Report. Rand Journal of Economics 37: 645-667.

Schor J., Fitzmaurice, C. (2015) Collaborating and Connecting: The emergence of the sharing economy, Handbook on Research on Sustainable Consumption, eds., Lucia Reisch and John Thogersen, (Cheltenham, UK: Edward Elgar), 2015.

Sundararajan, A. (2016). The Sharing Economy: The End of Employment and the Rise of Crowd-Based Capitalism. MIT Press.

Tadelis, S. (2016). Reputation and feedback systems in online platform markets. Annual Review of Economics, 8, 321-340.

Zervas, G., Proserpio D., Byers J. W. (2015). A First Look at Online Reputation on AirBnB, Where Every Stay is Above Average. Available at http://ssrn.com/abstract=2554500 
Figure 1: Screenshots of BlaBlaCar Website

\section{Bla Bla Car}

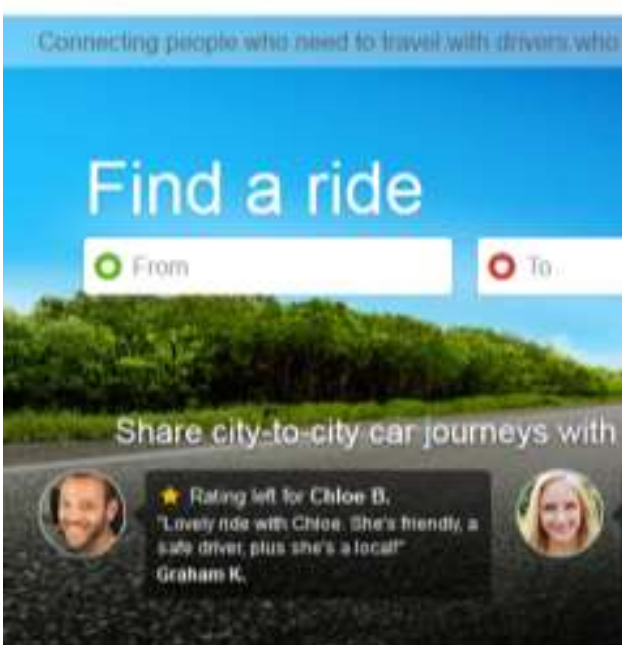

Your journey is insured

V vie gut assitanal intuance biv Aa hon decherge

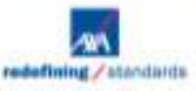

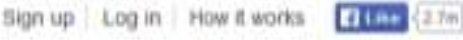

Drving somewhere? Offer a ride

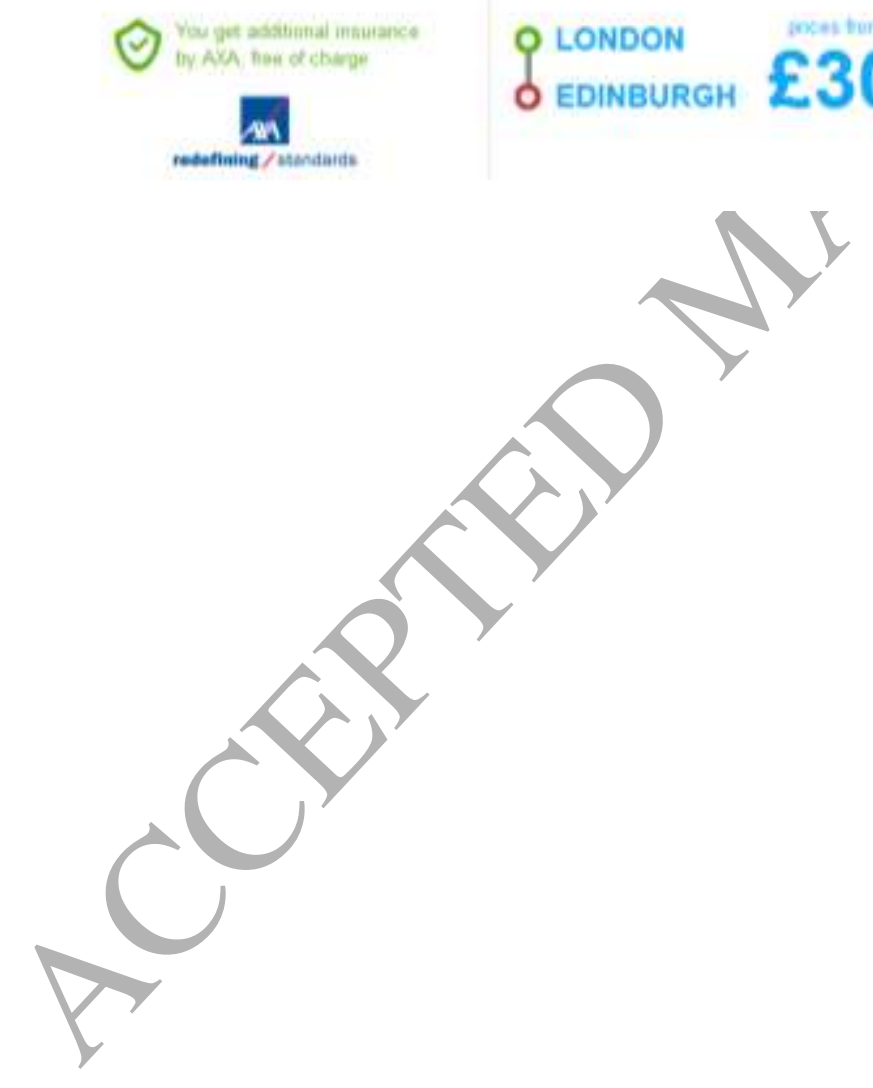

- Barna un wa Sarah A.

Trip whisad by whe nang oreat lobice accowarkaton Thanks, such a Sowhin C

Best Travel Prices

9 LONDON

$£ 30$

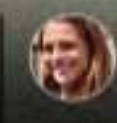

$\left(\begin{array}{l}4 \\ 6\end{array}\right)$

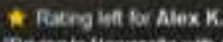

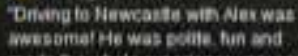
made no wholl espenience nery eas: Tanye 1 .

Download the app

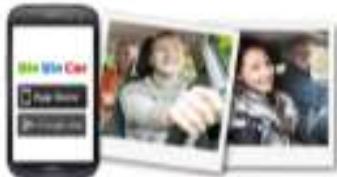




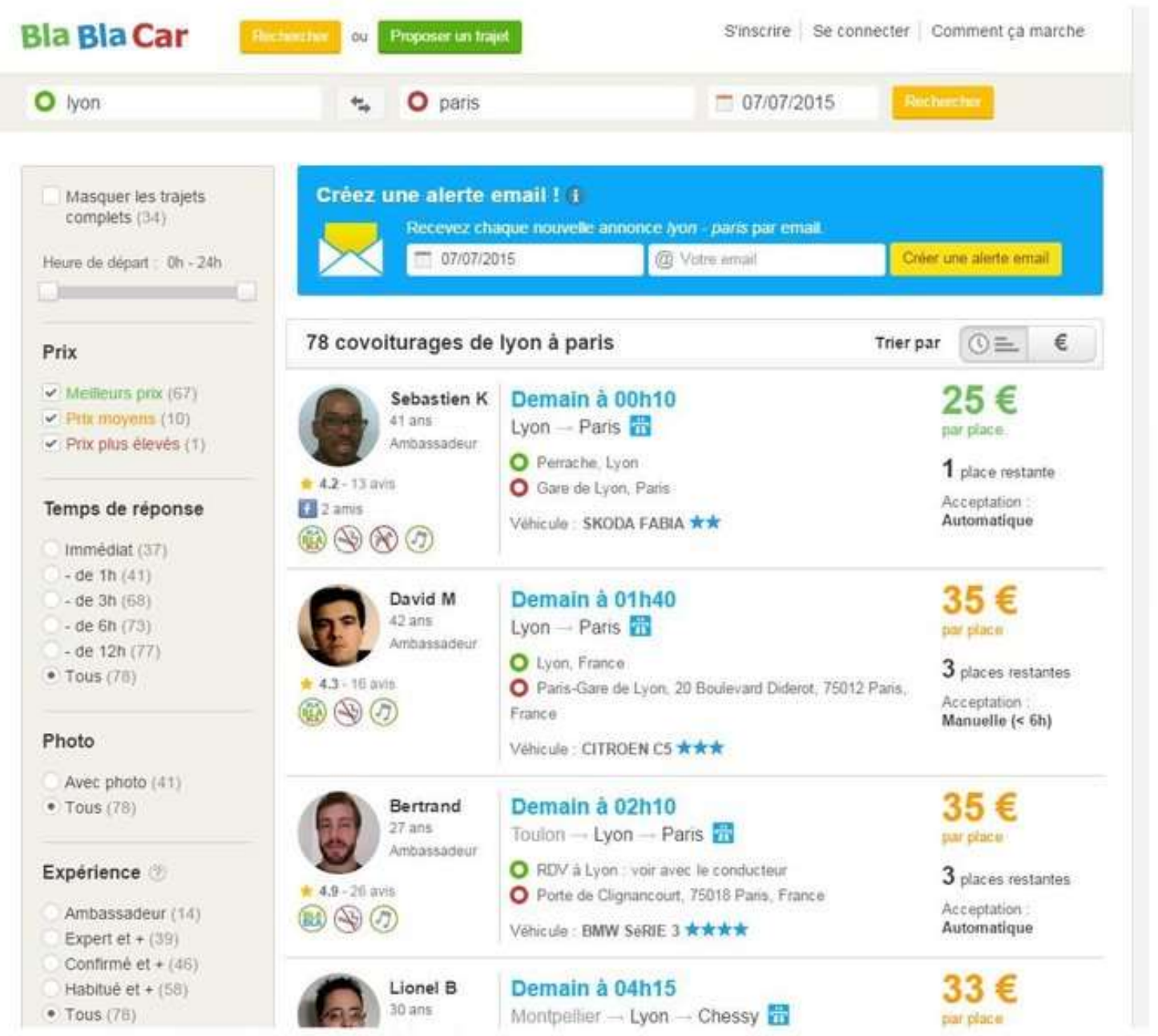

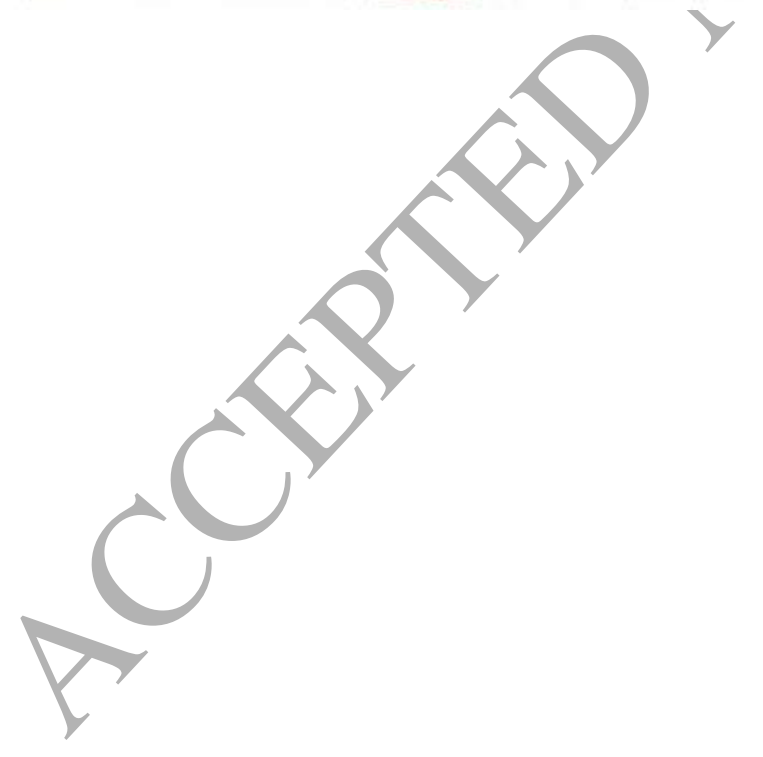


Table 1: BlaBlaCar's Driver Experience Levels

\begin{tabular}{|l|c|c|c|c|c|}
\hline & Newcomer & Intermediate & Experienced & Expert & Ambassador \\
\hline Profile completion & & $>60 \%$ & $>70 \%$ & $>80 \%$ & $>90 \%$ \\
\hline Number of ratings & & 1 rating & 3 ratings & 6 ratings & 12 ratings \\
\hline \% positive ratings & & $>60 \%$ & $>70 \%$ & $>80 \%$ & $>90 \%$ \\
\hline Seniority & & 1 month & 3 months & 6 months & 12 months \\
\hline
\end{tabular}


Table 2: Summary Statistics

\begin{tabular}{lc}
\hline Panel A: Unit of Observation = Driver \\
\hline Number of Same Trips & 3.728 \\
& $(6.652)$ \\
Number of Other Trips & 2.517 \\
& $(6.515)$ \\
Single-Trip Driver & 0.547 \\
& $(0.498)$ \\
Feedback Quantity & 8.366 \\
& $(18.987)$ \\
Feedback Quality & 99.041 \\
& $(6.049)$ \\
Driver Status & 2.659 \\
& $(1.446)$ \\
Car Class & 2.261 \\
& $(1.053)$ \\
Age & 36.009 \\
& $(13.293)$ \\
Female & 0.401 \\
& $(0.490)$ \\
French Name & 0.674 \\
& $(0.469)$ \\
Arabic Name & 0.050 \\
& $(0.218)$ \\
Photo Shown & 0.388 \\
& $(0.487)$ \\
Plays Music & 0.555 \\
& $(0.497)$ \\
Allows Pets & 0.088 \\
Allows Smoking & $(0.283)$ \\
Roundtrip & 0.067 \\
Manual Confirmation & $(0.250)$ \\
& 0.257 \\
$N$ & $0.437)$ \\
& 0.115 \\
& $(0.318)$ \\
\hline
\end{tabular}

Panel B: Unit of Observation = Trip, Drivers Grouped by Driver Status

\begin{tabular}{lcccccc}
\hline & All & Newcomer & Intermediate & Experienced & Expert & Ambassador \\
\hline Price & 13.461 & 14.211 & 13.574 & 13.589 & 13.748 & 11.923 \\
& $(9.409)$ & $(10.057)$ & $(9.185)$ & $(9.048)$ & $(9.047)$ & $(9.254)$ \\
Relative Price & -2.764 & -2.162 & -2.461 & -2.659 & -2.915 & -3.801 \\
& $(5.914)$ & $(6.013)$ & $(5.724)$ & $(5.686)$ & $(5.719)$ & $(6.219)$ \\
Seats Sold & 1.122 & 0.964 & 1.074 & 1.117 & 1.160 & 1.346 \\
& $(1.510)$ & $(1.418)$ & $(1.470)$ & $(1.494)$ & $(1.515)$ & $(1.641)$ \\
Fraction Sold & 0.625 & 0.553 & 0.602 & 0.611 & 0.630 & 0.752 \\
& $(0.433)$ & $(0.448)$ & $(0.436)$ & $(0.433)$ & $(0.427)$ & $(0.386)$ \\
All Seats Sold & 0.537 & 0.464 & 0.508 & 0.516 & 0.535 & 0.682 \\
& $(0.499)$ & $(0.499)$ & $(0.500)$ & $(0.500)$ & $(0.499)$ & $(0.466)$ \\
Avg. Price, Other Trips & 11.139 & 10.889 & 10.920 & 11.090 & 11.383 & 11.473 \\
& $(7.872)$ & $(8.349)$ & $(7.878)$ & $(7.691)$ & $(7.637)$ & $(7.590)$ \\
\hline$N$ & 920789 & 232547 & 177267 & 148579 & 188407 & 173989 \\
\hline
\end{tabular}

Notes: Standard deviations are in parentheses. 
Table 3: Price Results

\begin{tabular}{|c|c|c|}
\hline & $\begin{array}{l}(1) \\
\text { OLS }\end{array}$ & $\begin{array}{l}(2) \\
\text { IV }\end{array}$ \\
\hline Avg. Price, Other Trips & & $\begin{array}{c}0.010 \\
(0.000)^{* * *}\end{array}$ \\
\hline Feedback Quantity & $\begin{array}{c}-0.000 \\
(0.000)^{* *}\end{array}$ & $\begin{array}{c}-0.000 \\
(0.000)^{* *}\end{array}$ \\
\hline Feedback Quality & $\begin{array}{c}0.005 \\
(0.001)^{* * *}\end{array}$ & $\begin{array}{c}0.005 \\
(0.001)^{* * *}\end{array}$ \\
\hline Intermediate & $\begin{array}{c}-0.159 \\
(0.009)^{* * *}\end{array}$ & $\begin{array}{c}-0.154 \\
(0.009)^{* * *}\end{array}$ \\
\hline Experienced & $\begin{array}{c}-0.277 \\
(0.010)^{* * *}\end{array}$ & $\begin{array}{c}-0.271 \\
(0.010)^{* * *}\end{array}$ \\
\hline Expert & $\begin{array}{c}-0.415 \\
(0.010)^{* * *}\end{array}$ & $\begin{array}{c}-0.410 \\
(0.010)^{* * *}\end{array}$ \\
\hline Ambassador & $\begin{array}{c}-0.442 \\
(0.012)^{* * *}\end{array}$ & $\begin{array}{c}-0.436 \\
(0.012)^{* * *}\end{array}$ \\
\hline Car Class $=1$ & $\begin{array}{c}-0.374 \\
(0.018)^{* * *}\end{array}$ & $\begin{array}{c}-0.367 \\
(0.018)^{* * *}\end{array}$ \\
\hline Car Class $=2$ & $\begin{array}{c}-0.200 \\
(0.012)^{* * *}\end{array}$ & $\begin{array}{c}-0.192 \\
(0.012)^{* * *}\end{array}$ \\
\hline Car Class $=3$ & $\begin{array}{l}-0.017 \\
(0.012)\end{array}$ & $\begin{array}{c}-0.014 \\
(0.012)\end{array}$ \\
\hline Car Class $=4$ & $\begin{array}{c}0.298 \\
(0.016)^{* * *}\end{array}$ & $\begin{array}{c}0.294 \\
(0.016)^{* * *}\end{array}$ \\
\hline Age & $\begin{array}{c}0.008 \\
(0.000)^{* * *}\end{array}$ & $\begin{array}{c}0.007 \\
(0.000)^{* * *}\end{array}$ \\
\hline Female & $\begin{array}{c}0.124 \\
(0.007)^{* * *}\end{array}$ & $\begin{array}{l}0.124 \\
(0.007)^{* * *}\end{array}$ \\
\hline French Name & $\begin{array}{c}0.007 \\
(0.008)\end{array}$ & $\begin{array}{c}0.031 \\
(0.009)^{* * *}\end{array}$ \\
\hline Arabic Name & & $\begin{array}{c}-0.211 \\
(0.018)^{* * *}\end{array}$ \\
\hline Photo Shown & $\begin{array}{c}-0.022 \\
(0.007)^{* * *}\end{array}$ & $\begin{array}{c}-0.019 \\
(0.007)^{* * *}\end{array}$ \\
\hline Plays Music & $\begin{array}{l}-0.103 \\
(0.007)^{* * *}\end{array}$ & $\begin{array}{c}-0.100 \\
(0.007)^{* * *}\end{array}$ \\
\hline Allows Smok & $\begin{array}{c}-0.155 \\
(0.011)^{* * *} \\
0.115 \\
(0.013)^{* * *}\end{array}$ & $\begin{array}{c}-0.153 \\
(0.011)^{* * *} \\
0.115 \\
(0.013)^{* * *}\end{array}$ \\
\hline Roundtrip & $\begin{array}{c}0.149 \\
(0.007)^{* * *}\end{array}$ & $\begin{array}{c}0.144 \\
(0.007)^{* * *}\end{array}$ \\
\hline Manual Confirmation & $\begin{array}{c}0.489 \\
(0.008)^{* * *}\end{array}$ & $\begin{array}{c}0.480 \\
(0.008)^{* * *}\end{array}$ \\
\hline$N$ & 920789 & 920789 \\
\hline
\end{tabular}

First-Stage F Stat 1939.001

Notes: This table presents regressions where the dependent variable is the driver's price. Column (1) does not include the average-other-price instrument, while it is included in Column (2). The econometric specification is linear regression with trip fixed effects. For this and subsequent tables, standard errors are in parentheses; ${ }^{*} p<0.10,{ }^{* *} p<0.05,{ }^{* * *} p<0.01$. For this and subsequent tables, all continuous variables (feedback quantity, feedback quality, age, departure time trend) are included in quadratic form. These and all results are shown as average marginal effects. 
Table 4: Demand Results

\begin{tabular}{|c|c|c|c|c|}
\hline & \multicolumn{2}{|c|}{ Fraction Sold } & \multicolumn{2}{|c|}{ All Seats Sold } \\
\hline & (1) & (2) & (3) & (4) \\
\hline & OLS & IV & OLS & IV \\
\hline \multirow[t]{2}{*}{ Price } & -0.002 & -0.077 & -0.003 & -0.069 \\
\hline & $(0.000)^{* * *}$ & $(0.002)^{* * *}$ & $(0.000)^{* * *}$ & $(0.002)^{* * *}$ \\
\hline \multirow[t]{2}{*}{ Feedback Quantity } & 0.000 & 0.000 & 0.000 & 0.000 \\
\hline & $(0.000)^{* * *}$ & $(0.000)^{* * *}$ & $(0.000)^{* * *}$ & $(0.000)^{* * *}$ \\
\hline \multirow[t]{2}{*}{ Feedback Quality } & 0.002 & 0.002 & 0.002 & 0.002 \\
\hline & $(0.000)^{* * *}$ & $(0.000)^{* * *}$ & $(0.000)^{* * *}$ & $(0.000)^{* * *}$ \\
\hline \multirow[t]{2}{*}{ Intermediate } & 0.029 & 0.017 & 0.023 & 0.012 \\
\hline & $(0.001)^{* * *}$ & $(0.001)^{* * *}$ & $(0.001)^{* * *}$ & $(0.001)^{* * *}$ \\
\hline \multirow{2}{*}{ Experienced } & 0.033 & 0.012 & 0.027 & 0.009 \\
\hline & $(0.001)^{* * *}$ & $(0.002)^{* * *}$ & $(0.001)^{* * *}$ & $(0.002)^{* * *}$ \\
\hline \multirow[t]{2}{*}{ Expert } & 0.043 & 0.012 & 0.036 & 0.008 \\
\hline & $(0.001)^{* * *}$ & $(0.002)^{* * *}$ & $(0.001)^{* * *}$ & $(0.002)^{* * *}$ \\
\hline \multirow[t]{2}{*}{ Ambassador } & 0.085 & 0.052 & 0.086 & 0.057 \\
\hline & $(0.001)^{* * *}$ & $(0.002)^{* * *}$ & $(0.002)^{* * *}$ & $(0.002)^{* * *}$ \\
\hline \multirow[t]{2}{*}{ Car Class $=1$} & 0.040 & 0.011 & 0.040 & 0.015 \\
\hline & $(0.002)^{* * *}$ & $(0.003)^{* * *}$ & $(0.002)^{* * *}$ & $(0.003)^{* * *}$ \\
\hline \multirow[t]{2}{*}{ Car Class $=2$} & 0.046 & 0.031 & 0.049 & 0.036 \\
\hline & $(0.001)^{* * *}$ & $(0.002)^{*}$ & $(0.002)^{* * *}$ & $(0.002)^{* * *}$ \\
\hline \multirow[t]{2}{*}{ Car Class $=3$} & 0.026 & 0.025 & 0.035 & 0.034 \\
\hline & $(0.001)^{* * *}$ & $(0.002)^{* * *}$ & $(0.002)^{* * *}$ & $(0.002)^{* * *}$ \\
\hline \multirow[t]{2}{*}{ Car Class $=4$} & 0.014 & 0.037 & 0.021 & 0.041 \\
\hline & $(0.002)^{* * *}$ & $(0.002)^{* * *}$ & $(0.002)^{* * *}$ & $(0.002)^{* * *}$ \\
\hline \multirow[t]{2}{*}{ Age } & -0.001 & 0.000 & -0.000 & 0.000 \\
\hline & $(0.000)^{* * *}$ & $(0.000)$ & $(0.000)^{* * *}$ & $(0.000)^{* * *}$ \\
\hline \multirow[t]{2}{*}{ Female } & 0.018 & 0.028 & 0.043 & 0.051 \\
\hline & $(0.001)^{* * *}$ & $(0.001)^{* * *}$ & $(0.001)^{* * *}$ & $(0.001)^{* * *}$ \\
\hline \multirow[t]{2}{*}{ French Name } & 0,062 & 0.062 & 0.027 & 0.028 \\
\hline & $(0.001)^{* * *}$ & $(0.001)^{* * *}$ & $(0.001)^{* * *}$ & $(0.001)^{* * *}$ \\
\hline \multirow[t]{2}{*}{ Arabic Name } & & -0.074 & -0.076 & -0.089 \\
\hline & $02)^{3}$ & $(0.003)^{* * *}$ & $(0.002)^{* * *}$ & $(0.003)^{* * *}$ \\
\hline \multirow[t]{2}{*}{ Photo Shown } & 0.006 & 0.004 & 0.007 & 0.006 \\
\hline & $(0.001)^{* * *}$ & $(0.001)^{* * *}$ & $(0.001)^{* * *}$ & $(0.001)^{* * *}$ \\
\hline \multirow[t]{3}{*}{ Plays Music } & 0.029 & 0.022 & 0.029 & 0.022 \\
\hline & $(0.001)^{* * *}$ & $(0.001)^{* * *}$ & $(0.001)^{* * *}$ & $(0.001)^{* * *}$ \\
\hline & 0.000 & -0.012 & 0.000 & -0.010 \\
\hline \multirow{3}{*}{ Allows Smoking } & $(0.001)$ & $(0.002)^{* * *}$ & $(0.002)$ & $(0.002)^{* * *}$ \\
\hline & -0.015 & -0.006 & -0.017 & -0.009 \\
\hline & $(0.002)^{* * *}$ & $(0.002)^{* * *}$ & $(0.002)^{* * *}$ & $(0.002)^{* * *}$ \\
\hline \multirow[t]{2}{*}{ Roundtrip } & -0.010 & 0.002 & 0.001 & 0.011 \\
\hline & $(0.001)^{* * *}$ & $(0.001)$ & $(0.001)$ & $(0.001)^{* * *}$ \\
\hline \multirow[t]{2}{*}{ Manual Confirmation } & -0.477 & -0.441 & -0.582 & -0.550 \\
\hline & $(0.001)^{* * *}$ & $(0.002)^{* * *}$ & $(0.001)^{* * *}$ & $(0.002)^{* * *}$ \\
\hline$N$ & 920789 & 920789 & 920789 & 920789 \\
\hline
\end{tabular}

Notes: This table presents demand regressions. Columns (1) and (3) do not use the averageother-price variable to instrument for price, while Columns (2) and (4) do. The dependent variable in Columns (1)-(2) is the driver's fraction of seats sold. The dependent variable in Columns (3)-(4) equals one when fraction sold equals one. The econometric specification is linear regression with trip fixed effects. 
Table 5: Revenue Results

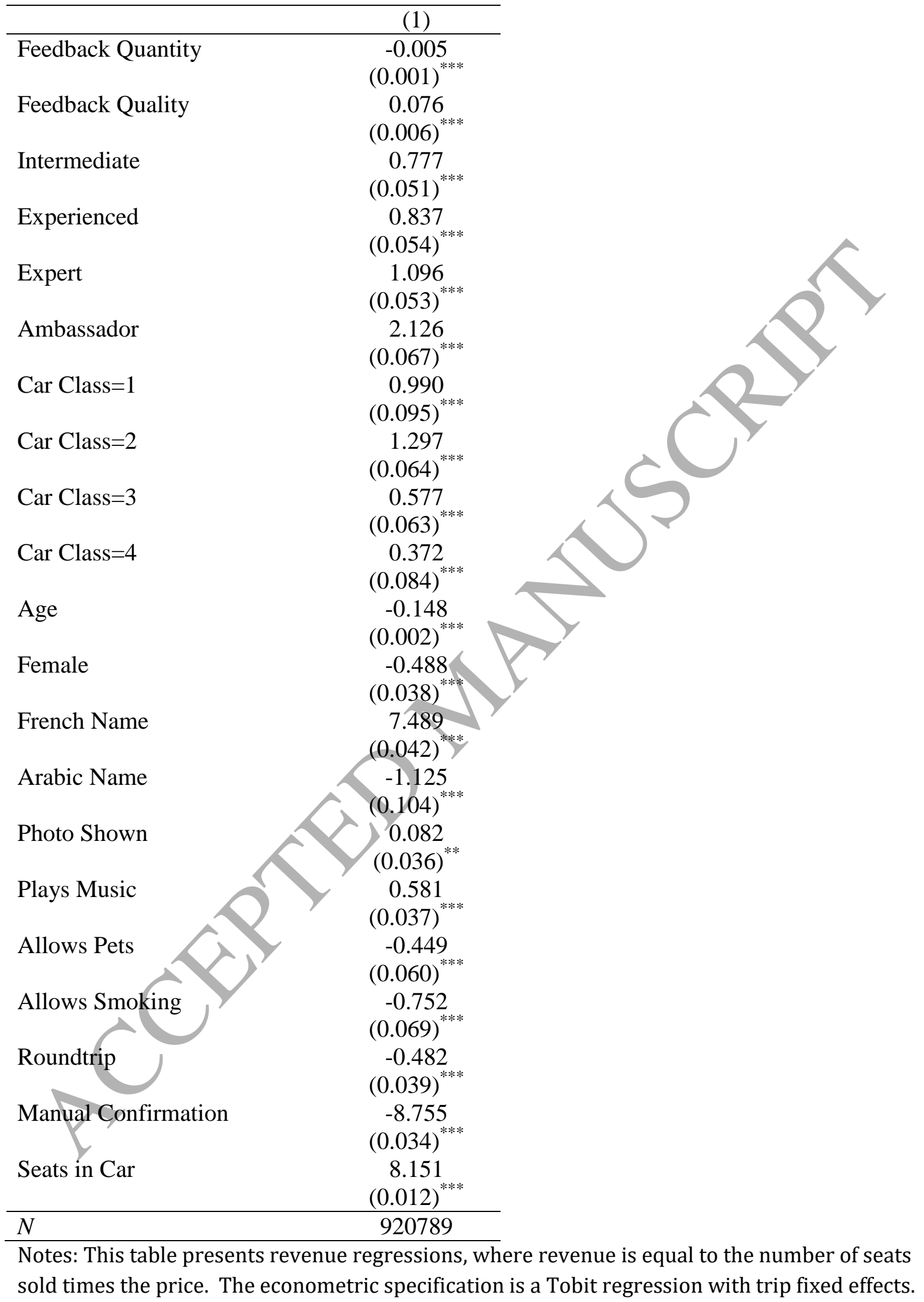


Table 6: Regression Results of Within-Driver Price Changes

\begin{tabular}{lc}
\hline & $(1)$ \\
\hline Feedback Quantity & -0.002 \\
Feedback Quality & $(0.000)^{* * *}$ \\
& -0.001 \\
Intermediate & $(0.002)$ \\
& -0.187 \\
Experienced & $(0.017)^{* * *}$ \\
Expert & -0.286 \\
& $(0.018)^{* * *}$ \\
Ambassador & -0.454 \\
& $(0.018)^{* * *}$ \\
\hline$N$ & -0.460 \\
\hline
\end{tabular}

Notes: This table present within-driver price regression results, including all drivers with at least eleven listings. The econometric specification is the same as in Column (2) in Table 3, with the exception of the inclusion of driver fixed effects in addition to trip fixed effects. Due to the inclusion of driver fixed effects, time-invariant covariates are not included. 
Table 7: Summary Statistics of Late-Tenure Listings Relative to Early-Tenure Relative Prices

\begin{tabular}{lccc}
\hline & $(1)$ & $(2)$ & $(3)$ \\
& $N$ & Price Range & Listings \\
\hline Price Category=1 & 2810 & $<-4.00$ & 10.992 \\
& & & $0.249)$ \\
Price Category=2 & 3702 & {$[-4.00,-2.25)$} & 10.894 \\
& & & $0.216)$ \\
Price Category=3 & 3663 & {$[-2.25,-1.00]$} & 11.786 \\
& & & $0.218)$ \\
Price Category=4 & 2814 & $>-1.00$ & 11.337 \\
& & & $0.248)$ \\
\hline
\end{tabular}

Notes: These summary statistics include all drivers with at least eleven listings who we first observe as a newcomer (status of one). Shown are price categories based on relative prices set during the first ten listings of each driver's tenure during our sample period. Listings are the count of late-tenure listings (i.e., listings eleven and later). Price categories are determined by quartiles of relative prices (i.e., the driver's price minus the recommended price).

Table 8: Summary Statistics of Late-Tenure Relative Prices Relative to Early-Tenure Sales

\begin{tabular}{|c|c|c|c|c|c|}
\hline & $\begin{array}{l}(1) \\
N\end{array}$ & $\begin{array}{c}(2) \\
\text { Sales Range }\end{array}$ & $\begin{array}{c}\text { (3) } \\
\text { Initial Price }\end{array}$ & $\begin{array}{c}\text { (4) } \\
\text { Later Price }\end{array}$ & $\begin{array}{c}\text { (5) } \\
\text { Price Change }\end{array}$ \\
\hline Sales Category=1 & 139 & $=0.00$ & $\begin{array}{c}-1.973 \\
(0.170)\end{array}$ & $\begin{array}{c}-2.413 \\
(0.084)\end{array}$ & $\begin{array}{c}-0.440 \\
(0.149)\end{array}$ \\
\hline Sales Category $=2$ & 4998 & $(0.00,0.50]$ & $\begin{array}{l}-2.1196 \\
(0.029)\end{array}$ & $\begin{array}{l}-2.317 \\
(0.017)\end{array}$ & $\begin{array}{l}-0.121 \\
(0.033)\end{array}$ \\
\hline Sales Category $=3$ & 7071 & & $\begin{array}{l}-2.776 \\
(0.023)\end{array}$ & $\begin{array}{l}-2.820 \\
(0.013)\end{array}$ & $\begin{array}{c}-0.044 \\
(0.024)\end{array}$ \\
\hline Sales Category $=4$ & 781 & & $\begin{array}{l}-3.991 \\
(0.141)\end{array}$ & $\begin{array}{c}-3.541 \\
(0.112)\end{array}$ & $\begin{array}{c}0.450 \\
(0.236)\end{array}$ \\
\hline
\end{tabular}

Notes: These summary statistics include all drivers with at least eleven listings who we first observe as a newcomer (status of one). Shown are sales categories based on the driver's average proportion of seats sold during her first ten listings during our sample period. Prices are the predicted relative price charged by drivers across their tenure on the platform, using the regression model from Table 3. Initial price is the average relative price measured for drivers' first observed trip, later price is the average relative price measured for drivers' who have had the average number of trips (17.2), and price change is the difference from initial price to later price. 


\section{Appendix A: Additional Figures and Tables}

Figure A1: Nonlinearities in the Effect of Age on Price

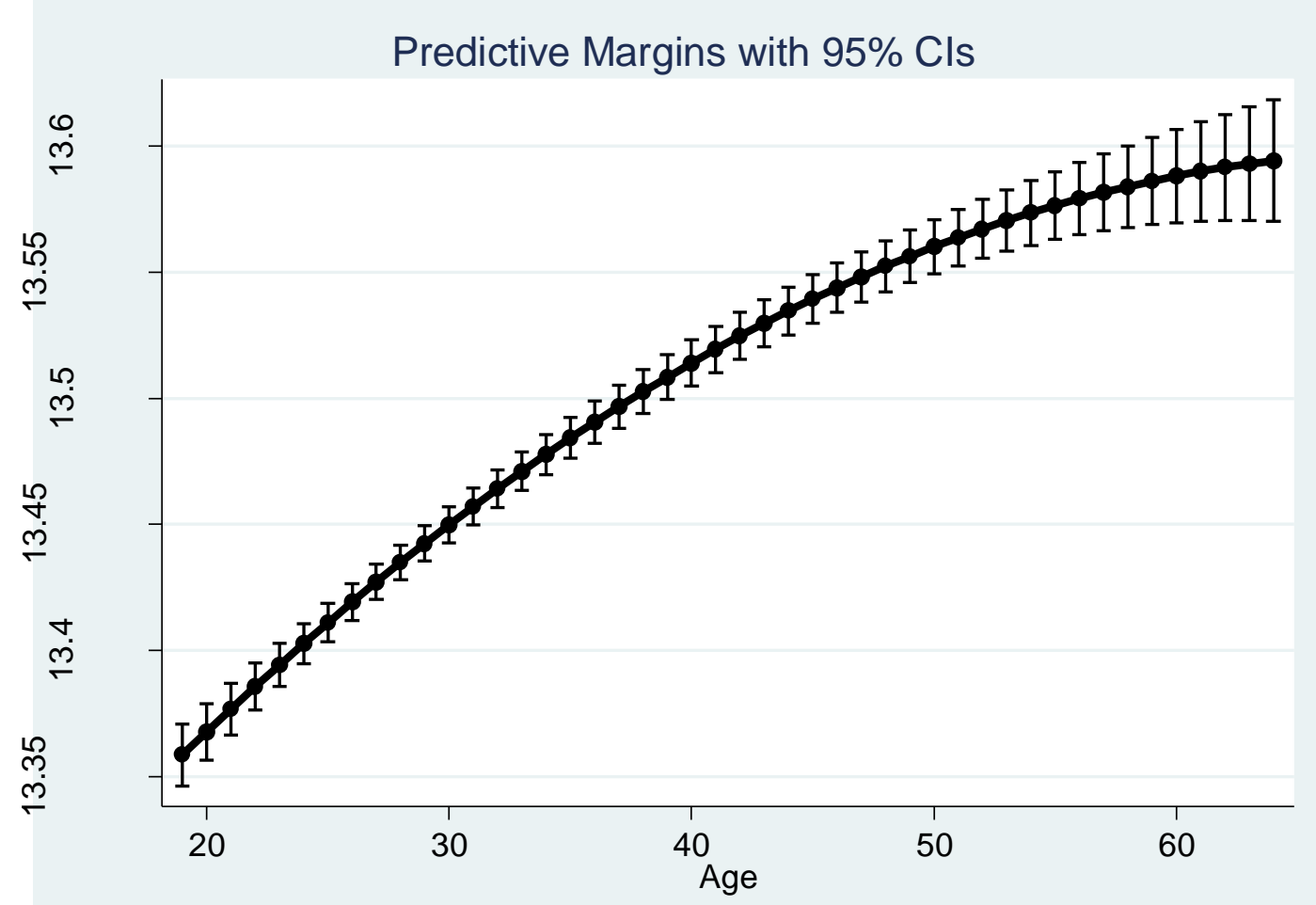

Figure A2: Nonlinearities in the Effect of Age on $\operatorname{Pr}($ Sale)

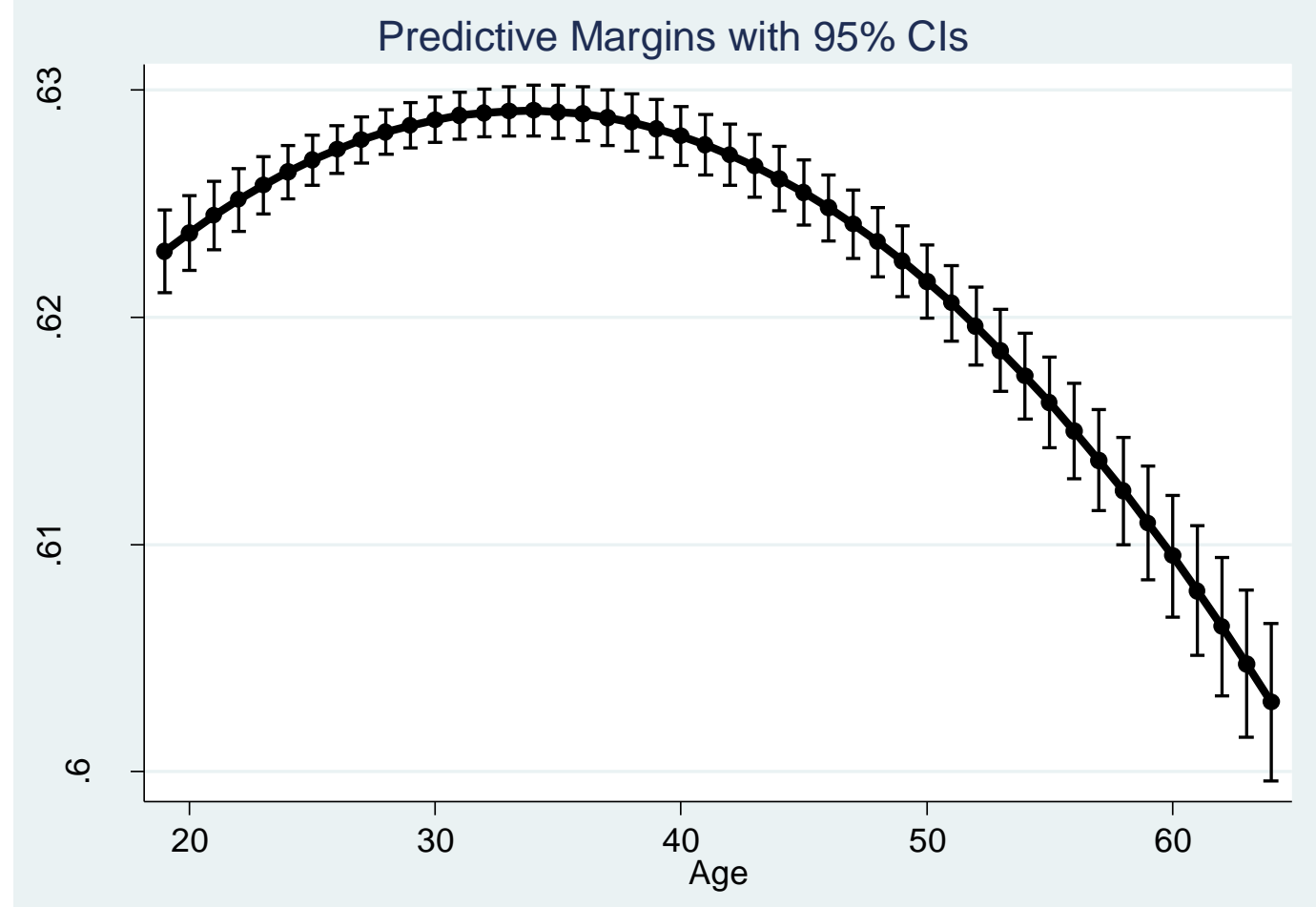


Table A1: Summary Statistics by Trip

\begin{tabular}{|c|c|c|c|c|c|c|c|c|}
\hline & \multirow[b]{2}{*}{$\mathrm{N}$} & \multicolumn{5}{|c|}{ Price } & \multirow[b]{2}{*}{$\begin{array}{c}\text { Fraction } \\
\text { Sold }\end{array}$} & \multirow[b]{2}{*}{$\begin{array}{c}\text { Distance } \\
(\mathrm{km})\end{array}$} \\
\hline & & Mean & StdDev & $\mathrm{P} 1$ & Median & P99 & & \\
\hline Aix Avignon & 14505 & 5.179 & 1.531 & 2 & 5 & 10 & 0.604 & 81 \\
\hline Amiens Beauvais & 3400 & 4.274 & 1.316 & 2 & 4 & 7 & 0.659 & 66 \\
\hline Angers LeMans & 22514 & 6.184 & 1.378 & 3 & 6 & 10 & 0.568 & 97 \\
\hline Besancon Dijon & 3026 & 5.885 & 2.170 & 2 & 6 & 10 & 0.468 & 93 \\
\hline Bordeaux Nantes & 36577 & 21.165 & 2.350 & 15 & 21 & 27 & 0.624 & 353 \\
\hline Brest SaintBrieuc & 7899 & 8.060 & 1.700 & 4 & 8 & 13 & 0.442 & 144 \\
\hline Caen Rennes & 22892 & 10.979 & 1.742 & 7 & 11 & 15 & 0.504 & 185 \\
\hline Clermont Lyon & 28908 & 12.362 & 1.984 & 8 & 13 & 17 & 0.560 & 166 \\
\hline Dijon Besancon & 3217 & 5.881 & 2.033 & 2 & 6 & 12 & 0.454 & 93 \\
\hline Grenoble Lyon & 23893 & 6.847 & 1.465 & 4 & 7 & 10 & 0.502 & 105 \\
\hline LeHavre Caen & 7978 & 5.820 & 1.094 & 3 & 6 & 9 & 0.529 & 96 \\
\hline LeMans Tours & 14096 & 5.650 & 1.435 & 3 & 6 & 10 & 0.552 & 102 \\
\hline Lens Paris & 44913 & 14.309 & 1.680 & 10 & 15 & 19 & 0.588 & 199 \\
\hline Lille Paris & 49450 & 14.559 & 1.615 & 10 & 15 & 20 & 0.602 & 220 \\
\hline Limoge Toulouse & 19734 & 17.998 & 3.020 & 12 & 18 & 25 & 0.548 & 291 \\
\hline Lyon Grenoble & 24021 & 6.886 & 1.669 & 4 & & 10 & 0.494 & 105 \\
\hline Lyon Paris & 48316 & 29.145 & 3.419 & 20 & 30 & 38 & 0.666 & 466 \\
\hline Marseille Nice & 5162 & 13.223 & 3.156 & & 13 & 21 & 0.385 & 198 \\
\hline Metz Nancy & 30958 & 3.547 & 0.995 & 1 & 4 & 6 & 0.938 & 60 \\
\hline Montpellier Marseille & 15327 & 10.917 & 2.145 & 7 & 11 & 16 & 0.511 & 169 \\
\hline Nancy Strasbourg & 4326 & 9.185 & 2.306 & 3 & 10 & 17 & 0.458 & 156 \\
\hline Nantes Bordeaux & 36524 & 21.133 & 2.275 & 15 & 21 & 26 & 0.614 & 353 \\
\hline Nantes Rennes & 51978 & 5.870 & 1.400 & 4 & 6 & 9 & 0.507 & 113 \\
\hline Nice Toulon & 2004 & 10.885 & 2.782 & 7 & 10 & 17 & 0.299 & 150 \\
\hline Nimes Montpellier & 89098 & 3.065 & 0.817 & 1 & 3 & 5 & 0.971 & 58 \\
\hline Orleans Paris & 24963 & 8,266 & 2.460 & 4 & 8 & 12 & 0.549 & 133 \\
\hline Paris Brest & 17063 & 36.140 & 3.717 & 25 & 37 & 45 & 0.712 & 591 \\
\hline Paris Caen & 17997 & 15.002 & 1.947 & 10 & 15 & 20 & 0.524 & 234 \\
\hline Paris Lyon & 46706 & 29.101 & 3.680 & 20 & 30 & 38 & 0.658 & 466 \\
\hline Paris Marseille & 5282 & 47.337 & 9.809 & 19 & 50 & 71 & 0.608 & 774 \\
\hline Pau Bordeaux & 12415 & 13.918 & 2.595 & 9 & 14 & 20 & 0.465 & 218 \\
\hline Perpignan Narbonne & 22578 & 4.205 & 1.277 & 1 & 4 & 7 & 0.759 & 66 \\
\hline Reims Troyes & 9190 & 8.082 & 1.965 & 5 & 8 & 13 & 0.466 & 127 \\
\hline Rennes Brest & 11358 & 12.758 & 2.531 & 8 & 12 & 19 & 0.458 & 243 \\
\hline Rouen Paris & 13462 & 8.734 & 1.501 & 5 & 9 & 12 & 0.488 & 136 \\
\hline SaintEtienne Clermont & 35504 & 22.676 & 10.183 & 3 & 23 & 49 & 0.577 & 144 \\
\hline Strasbourg Colmard & 8192 & 4.314 & 1.162 & 1 & 4 & 8 & 0.732 & 76 \\
\hline Toulon Aix & 10502 & 5.448 & 1.771 & 1 & 6 & 10 & 0.540 & 84 \\
\hline Toulouse Bordeaux & 47913 & 15.111 & 2.019 & 10 & 15 & 20 & 0.539 & 245 \\
\hline Tours Paris & 26948 & 15.434 & 2.850 & 10 & 15 & 21 & 0.628 & 240 \\
\hline Total y & 920789 & 13.461 & 9.409 & 2 & 12 & 40 & 0.625 & \\
\hline
\end{tabular}

Notes: This table presents trip-level summary statistics. Shown are the number of observations in the data by trip, summary statistics for price, mean fraction of seats sold, fraction of seats sold, and the distance between the two cities in kilometers. The statistics shown for price are the mean, standard deviation, $1^{\text {st }}$ percentile, median, and $99^{\text {th }}$ percentile. 
Table A2: Tabulation of Relative Price

\begin{tabular}{lccc}
\hline & Frequency & Percent & Cumulative \\
\hline$>-10$ & 53757 & 5.84 & 5.84 \\
-10 & 8325 & 0.90 & 6.74 \\
-9 & 11164 & 1.21 & 7.95 \\
-8 & 15242 & 1.66 & 9.61 \\
-7 & 22794 & 2.48 & 12.09 \\
-6 & 36176 & 3.93 & 16.01 \\
-5 & 45724 & 4.97 & 20.98 \\
-4 & 81057 & 8.80 & 29.78 \\
-3 & 95614 & 10.38 & 40.17 \\
-2 & 138288 & 15.02 & 55.19 \\
-1 & 169677 & 18.43 & 73.61 \\
0 & 119305 & 12.96 & 86.57 \\
1 & 34929 & 3.79 & 90.36 \\
2 & 25910 & 2.81 & 93.18 \\
3 & 21131 & 2.29 & 95.47 \\
4 & 12516 & 1.36 & 96.83 \\
5 & 8541 & 0.93 & 97.76 \\
6 & 5921 & 0.64 & 98.40 \\
7 & 3918 & 0.43 & 98.83 \\
8 & 1906 & 0.21 & 99.03 \\
9 & 1082 & 0.12 & 99.15 \\
10 & 745 & 0.08 & 99.23 \\
$<10$ & 7067 & 0.77 & 100.00 \\
\hline Total & 920789 & 100.00 &
\end{tabular}

Notes: This table presents a tabulation of drivers' prices minus the recommended price, that is, the relative price.

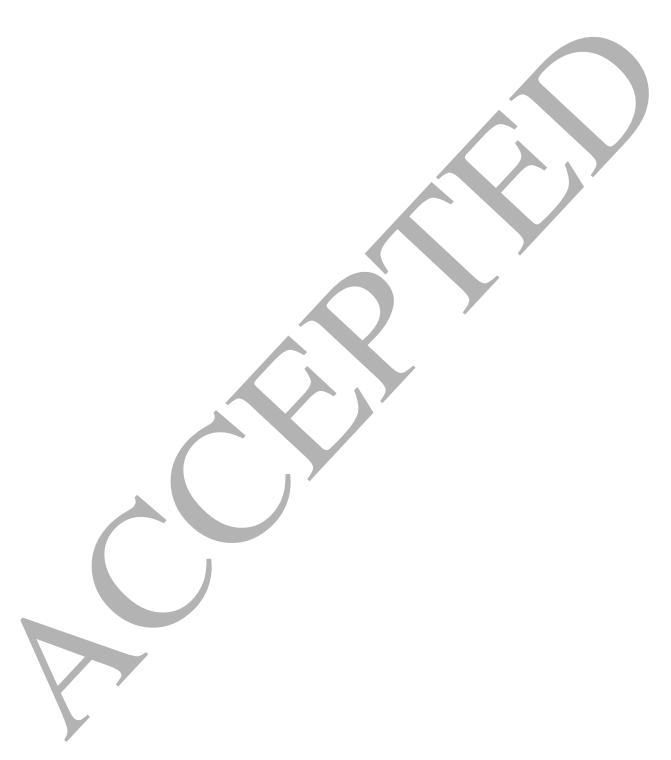


Table A3: Regression Results of Departure Characteristics

\begin{tabular}{lccc}
\hline & $(1)$ & $(2)$ & $(3)$ \\
& Price & Fraction Sold & All Seats Sold \\
\hline Departure=Monday & -0.099 & -0.056 & -0.059 \\
& $(0.011)^{* * *}$ & $(0.002)^{* * *}$ & $(0.002)^{* * *}$ \\
Departure=Tuesday & -0.123 & -0.098 & -0.105 \\
& $(0.013)^{* * *}$ & $(0.002)^{* * *}$ & $(0.002)^{* * *}$ \\
Departure=Wednesday & -0.071 & -0.093 & -0.103 \\
& $(0.013)^{* * *}$ & $(0.002)^{* * *}$ & $(0.002)^{* * *}$ \\
Departure=Thursday & 0.021 & -0.058 & -0.064 \\
& $(0.012)^{*}$ & $(0.002)^{* * *}$ & $(0.002)^{* * *}$ \\
Departure=Friday & -0.037 & -0.022 & -0.025 \\
& $(0.009)^{* * *}$ & $(0.001)^{* * *}$ & $(0.001)^{* * *}$ \\
Departure=Saturday & 0.075 & 0.004 & 0.002 \\
& $(0.011)^{* * *}$ & $(0.002)^{* * *}$ & $(0.002)$ \\
Departure=[6AM,12PM] & 0.014 & 0.055 & 0.070 \\
& $(0.023)$ & $(0.003)^{* * *}$ & $(0.003)^{* * *}$ \\
Departure=[12PM,6PM] & -0.064 & 0.054 & 0.068 \\
& $(0.023)^{* * *}$ & $(0.003)^{* * *}$ & $(0.003)^{* * *}$ \\
Departure=[6PM,12AM] & -0.209 & 0.011 & 0.022 \\
& $(0.024)^{* * *}$ & $(0.003)^{* * *}$ & $(0.004)^{* * *}$ \\
Departure Time Trend & -0.004 & -0.000 & 0.000 \\
& $(0.000)^{* * *}$ & $(0.000)$ & $(0.000)^{* * *}$ \\
\hline$N$ & 920789 & 920789 & 920789 \\
\hline
\end{tabular}

Notes: This table presents additional covariates from the earlier price and demand regressions. Column (1) of Table 5 present results from the same regression as in Column (2) of Table 3, respectively. Columns (2) and (3) of Table 5 present results from the same regressions as in Columns (2) and (4) of Table 4, respectively. These results are from the exact same regression, broken into multiple tables for ease of presentation. 
Table A4: Additional Regression Results for Price

(1)

(2)

(3)

(4)

Avg. Price, Other Trips

Feedback Quantity

Feedback Quantity

Feedback Quality

$(0.000)^{* *}$

0.005

$(0.001)^{* * *}$

$-0.159$

Intermediate

-0.211
$(0.009)^{* * *}$

$-0.166$

$-0.347$

$(0.009)^{* * *}$

Experienced

$(0.010)^{* * *}$

$-0.285$

$(0.009)^{* * *}$

$-0.277$

Expert

$-0.499$

$(0.010)^{* * *}$

$(0.009)^{* * *}$

$-0.416$

Ambassador

$-0.549$

$(0.009)^{* * *}$

$(0.010)^{* * *}$

$-0.415$

$(0.010)$

$-0.414$

Age

$(0.010)^{* * *}$

$(0.010)^{* * *}$

0.009

$-0.443$

$(0.012)^{* *}$

$(0.000)^{* * *}$

0.008

$(0.000)^{* * *}$

Female

0.072

French Name

$(0.007) *$

$-0.009$

0.123

$(0.007)^{* * *}$

$-0.001$

(0.008)

$-0.216$

Arabic Name

(0.008)

$-0.196$

$(0.018)^{* * *}$

$-0.022$

Photo Shown

$(0.018)$
-0.027

$(0.007)^{* * *}$

Plays Music

$-0.099$

$(0.007)^{* * *}$

Allows Pets

$-0.171$

$(0.011)^{* * *}$

0.084

Allows Smoking

$(0.013)^{* * *}$

0.150

Roundtrip

$(0.007)^{* * *}$

0.491

$(0.007)^{* * *}$

$-0.103$

$(0.007)^{* * *}$

$-0.156$

$(0.011)^{* * *}$

0.115

$(0.013)^{* * *}$

0.149

$(0.007)^{* * *}$

0.489

$(0.000)^{* * *}$

Manual Confirmation

$(0.008)^{* * *}$

$(0.008)^{* * *}$

$-0.375$

$-0.000$

$(0.000)^{* *}$

0.005

$(0.001)^{* * *}$

$-0.154$

$(0.009)^{* * *}$

$-0.271$

$(0.010)^{* * *}$

$-0.410$

$(0.010)^{* * *}$

$-0.437$

$(0.012)^{* * *}$

0.007

$(0.000)^{* * *}$

0.124

$(0.007)^{* * *}$

0.022

$(0.009)^{* *}$

$-0.239$

$(0.018)^{* * *}$

$-0.019$

$(0.007)^{* * *}$

$-0.100$

$(0.007)^{* * *}$

$-0.154$

Car Class $=1$

$(0.018)^{* * *}$

$-0.200$

$(0.011)^{* * *}$

0.115

$(0.013)^{* * *}$

0.144

$(0.007)^{* * *}$

0.480
$(0.008)^{* * *}$

$-0.368$

Car Class $=2$

$(0.012)^{* * *}$

$-0.016$

$(0.018)^{* * *}$

$-0.192$

Car Class $=3$

(0.012)

$(0.012)^{* * *}$

0.298

$-0.013$

(0.012)

Car Class $=4$

$(0.016)^{* * *}$

0.293

920789

$(0.016)^{* * *}$

920789

920789

920789

Notes: This table presents additional specifications for price. Columns (3) and (4) match

Columns (1) and (2) from Table 3. 
Table A5: Demand Regression with only Multiple-Trip Drivers

\begin{tabular}{|c|c|c|c|c|}
\hline & $\begin{array}{c}\text { Fraction Sold } \\
(1) \\
\text { OLS }\end{array}$ & $\begin{array}{l}\text { (2) } \\
\text { IV }\end{array}$ & $\begin{array}{c}\text { All Seats Sold } \\
\text { (3) } \\
\text { OLS }\end{array}$ & $\begin{array}{l}\text { (4) } \\
\text { IV }\end{array}$ \\
\hline Price & $\begin{array}{c}-0.002 \\
(0.000)^{\text {**** }}\end{array}$ & $\begin{array}{c}-0.025 \\
(0.002)^{* * *}\end{array}$ & $\begin{array}{c}-0.002 \\
(0.000)^{* * *}\end{array}$ & $\begin{array}{c}0.006 \\
(0.002)^{* * * *}\end{array}$ \\
\hline Feedback Quantity & $\begin{array}{c}0.000 \\
(0.000)^{* * *}\end{array}$ & $\begin{array}{c}0.000 \\
(0.000)^{* * *}\end{array}$ & $\begin{array}{c}0.000 \\
(0.000)^{* * * *}\end{array}$ & $\begin{array}{c}0.000 \\
(0.000)^{* * *}\end{array}$ \\
\hline Feedback Quality & $\begin{array}{c}0.002 \\
(0.000)^{* * * *}\end{array}$ & $\begin{array}{c}0.002 \\
(0.000)^{* * *}\end{array}$ & $\begin{array}{c}0.002 \\
(0.000)^{* * *}\end{array}$ & $\begin{array}{c}0.002 \\
(0.000)^{* * *}\end{array}$ \\
\hline Intermediate & $\begin{array}{c}0.023 \\
(0.001)^{* * * *}\end{array}$ & $\begin{array}{c}0.019 \\
(0.001)^{\text {**** }}\end{array}$ & $\begin{array}{c}0.018 \\
(0.001)^{* * * *}\end{array}$ & $\begin{array}{c}0.019 \\
(0.002)^{\text {**** }}\end{array}$ \\
\hline Experienced & $\begin{array}{c}0.024 \\
(0.001)^{* * *}\end{array}$ & $\begin{array}{c}0.017 \\
(0.002)^{* * *}\end{array}$ & $\begin{array}{c}0.021 \\
(0.002)^{* * *}\end{array}$ & $\begin{array}{c}0.023 \\
(0.002)^{* * *}\end{array}$ \\
\hline Expert & $\begin{array}{c}0.034 \\
(0.001)^{* * * *}\end{array}$ & $\begin{array}{c}0.024 \\
(0.002)^{* * *}\end{array}$ & $\begin{array}{c}0.030 \\
(0.002)^{* * * *}\end{array}$ & $\begin{array}{c}0.033 \\
(0.002)^{* * *}\end{array}$ \\
\hline Ambassador & $\begin{array}{c}0.081 \\
(0.002)^{\text {**** }}\end{array}$ & $\begin{array}{c}0.070 \\
(0.002)^{* * *}\end{array}$ & $\begin{array}{c}0.088 \\
(0.002)^{* * *}\end{array}$ & $\begin{array}{c}0.092 \\
(0.002)^{* * * *}\end{array}$ \\
\hline Car Class $=1$ & $\begin{array}{c}0.036 \\
(0.002)^{* * * *}\end{array}$ & $\begin{array}{c}0.027 \\
(0.003)^{* * * *}\end{array}$ & $\begin{array}{c}0.037 \\
(0.003)^{* * *}\end{array}$ & $\begin{array}{c}0.040 \\
(0.003)^{* * *}\end{array}$ \\
\hline Car Class $=2$ & $\begin{array}{c}0.043 \\
(0.002)^{* * *}\end{array}$ & $\begin{array}{c}0.038 \\
(0.002)^{* * * * *}\end{array}$ & $\begin{array}{c}0.049 \\
(0.002)^{* * *}\end{array}$ & $\begin{array}{c}0.051 \\
(0.002)^{* * *}\end{array}$ \\
\hline Car Class $=3$ & $\begin{array}{c}0.024 \\
(0.002)^{* * * *}\end{array}$ & $\begin{array}{l}0.023 \\
(0.002)^{* * *}\end{array}$ & $\begin{array}{c}0.037 \\
(0.002)^{\text {**** }}\end{array}$ & $\begin{array}{c}0.037 \\
(0.002)^{\text {**** }}\end{array}$ \\
\hline Car Class $=4$ & $\begin{array}{l}0.016 \\
(0.002)^{* * * *}\end{array}$ & $\begin{array}{l}0.022 \\
(0.002)^{* * *}\end{array}$ & $\begin{array}{c}0.030 \\
(0.002)^{* * * *}\end{array}$ & $\begin{array}{c}0.027 \\
(0.003)^{* * *}\end{array}$ \\
\hline Age & $\begin{array}{c}-0.002 \\
(0.000)^{* * * * *}\end{array}$ & $\begin{array}{c}-0.001 \\
(0.000)^{* * *}\end{array}$ & $\begin{array}{c}-0.001 \\
(0.000)^{* * *}\end{array}$ & $\begin{array}{c}-0.001 \\
(0.000)^{* * *}\end{array}$ \\
\hline Female & 0.002 & $\begin{array}{c}0.005 \\
(0.001)^{* * * *}\end{array}$ & $\begin{array}{c}0.025 \\
(0.001)^{* * * *}\end{array}$ & $\begin{array}{c}0.024 \\
(0.001)^{* * * *}\end{array}$ \\
\hline French Name & 0125 & $\begin{array}{c}0.132 \\
(0.001)^{* * * *}\end{array}$ & $\begin{array}{c}0.116 \\
(0.002)^{* * * *}\end{array}$ & $\begin{array}{c}0.117 \\
(0.002)^{* * *}\end{array}$ \\
\hline Arabic Name & $\begin{array}{c}-0.047 \\
(0.003)^{* * * *}\end{array}$ & $\begin{array}{c}-0.053 \\
(0.003)^{* * *}\end{array}$ & $\begin{array}{c}-0.065 \\
(0.003)^{* * *}\end{array}$ & $\begin{array}{c}-0.063 \\
(0.003)^{* * *}\end{array}$ \\
\hline Photo Shown & $\begin{array}{c}0.005 \\
(0.001)^{* * *}\end{array}$ & $\begin{array}{c}0.005 \\
(0.001)^{* * *}\end{array}$ & $\begin{array}{c}0.007 \\
(0.001)^{* * *}\end{array}$ & $\begin{array}{c}0.007 \\
(0.001)^{* * *}\end{array}$ \\
\hline Plays Music & $\begin{array}{l}0.025 \\
(0.001)^{* * * *}\end{array}$ & $\begin{array}{c}0.023 \\
(0.001)^{* * *}\end{array}$ & $\begin{array}{c}0.024 \\
(0.001)^{* * *}\end{array}$ & $\begin{array}{c}0.025 \\
(0.001)^{* * *}\end{array}$ \\
\hline Allows Pets & $\begin{array}{l}-0.001 \\
(0.002)\end{array}$ & $\begin{array}{l}-0.005 \\
(0.002)^{* * *}\end{array}$ & $\begin{array}{l}-0.001 \\
(0.002)\end{array}$ & $\begin{array}{c}0.000 \\
(0.002)\end{array}$ \\
\hline Allows Smoking & $\begin{array}{c}-0.015 \\
(0.002)^{* * *}\end{array}$ & $\begin{array}{c}-0.013 \\
(0.002)^{* * *}\end{array}$ & $\begin{array}{c}-0.019 \\
(0.002)^{* * *}\end{array}$ & $\begin{array}{c}-0.020 \\
(0.002)^{* * *}\end{array}$ \\
\hline Roundtrip & $\begin{array}{c}-0.013 \\
(0.001)^{* * *}\end{array}$ & $\begin{array}{c}-0.009 \\
(0.001)^{* * * *}\end{array}$ & $\begin{array}{c}0.001 \\
(0.001)\end{array}$ & $\begin{array}{l}-0.000 \\
(0.001)\end{array}$ \\
\hline Manual Confirmation & $\begin{array}{c}-0.435 \\
(0.001)^{* * * *}\end{array}$ & $\begin{array}{c}-0.423 \\
(0.001)^{* * * *}\end{array}$ & $\begin{array}{c}-0.542^{* * * *} \\
(0.001)^{* * *}\end{array}$ & $\begin{array}{c}-0.546 \\
(0.002)^{* * * *}\end{array}$ \\
\hline$N$ & 725202 & 725202 & 725202 & 725202 \\
\hline
\end{tabular}

Notes: This table follows Table 4 but only includes multiple-trip drivers (i.e., drivers who were observed with listings between more than one pair of cities). 


\section{Appendix B: Robustness Checks Using Alternative Instruments}

In this appendix, we introduce two strategies for constructing alternative instruments and demonstrate the robustness of the main results. First, we use the time series dimension of the data and look at drivers who offered listings of the trip in question during the week prior to the week in question. If the driver in question listed the trip in the prior week also, she is excluded from the construction of these instruments. Specifically, we use the one week lag of characteristics of other drivers on the same trip in the prior week.

The instrument we use is the average fraction of orange or red prices (i.e., not green prices) for the prices set by other drivers on the same trip in the prior week. We investigated a number of alternative instruments but find that they do not pass validity tests (i.e., there is evidence that they are weak). While this type of intertemporal instrument is common in empirical microeconomics, we do not find that our covariates are particularly strong in these data. To provide evidence of the robustness of our results, we include the strongest of such instruments: average fraction of orange or red prices. Given concerns over weak instruments, we include this lagged instrument along with our preferred instrument: the average-other-price instrument. The results are in Table B1. The first column reproduces Column (2) from Table 3 for comparison.

\section{[Insert Table B1]}

The second strategy for constructing alternative instruments is to use a similar strategy used for the average-other-price instrument of exploiting the panel nature of the data. Here we use the average characteristics of other drivers than the driver in question's modal trip (other than the trip in question) during the same week. First, we construct the average feedback quantity of other drivers on the driver in question's modal trip in 
the same week. Second, we construct the average fraction of orange or red prices (i.e., not green prices) on the modal trip in the same week. The results are in Table B2. The first column reproduces Column (1) from Table 3 for comparison.

\section{[Insert Table B2]}

In both tables, the main results are highly robust. First, driver experience matters more than driver reputation, but both positively affect sales, with the largest effect coming from the move to ambassador status (i.e., the highest level of experience). Second, driver demographics matter, with females and drivers with French names selling more seats and drivers with Arabic names selling fewer seats. The price elasticity itself is robustly statistically significantly negative and of similar magnitude across each column.

These results are intended to demonstrate the robustness of our analysis to alternative approaches to controlling for the endogeneity of price in the estimation of the effects of driver characteristics (experience and demographics) on demand. We conclude that all of the results carry over. 
Table B1: Robustness Checks Using First Set of Alternative Instruments

\begin{tabular}{|c|c|c|}
\hline & $(1)$ & $(2)$ \\
\hline \multirow[t]{2}{*}{ Price } & -0.077 & -0.060 \\
\hline & $(0.002)^{* * *}$ & $(0.002)^{* * *}$ \\
\hline \multirow[t]{2}{*}{ Feedback Quantity } & 0.000 & 0.000 \\
\hline & $(0.000)^{* * *}$ & $(0.000)^{* * *}$ \\
\hline \multirow[t]{2}{*}{ Feedback Quality } & 0.002 & 0.002 \\
\hline & $(0.000)^{* * *}$ & $(0.000)^{* * *}$ \\
\hline \multirow[t]{2}{*}{ Intermediate } & 0.017 & 0.019 \\
\hline & $(0.001)^{* * *}$ & $(0.001)^{* * *}$ \\
\hline \multirow[t]{2}{*}{ Experienced } & 0.012 & 0.017 \\
\hline & $(0.002)^{* * *}$ & $(0.001)^{* * *}$ \\
\hline \multirow[t]{2}{*}{ Expert } & 0.012 & 0.019 \\
\hline & $(0.002)^{* * *}$ & $(0.002)^{* * *}$ \\
\hline \multirow[t]{2}{*}{ Ambassador } & 0.052 & 0.059 \\
\hline & $(0.002)^{* * *}$ & $(0.002)^{* * *}$ \\
\hline \multirow[t]{2}{*}{ Car Class $=1$} & 0.011 & 0.018 \\
\hline & $(0.003)^{* * *}$ & $(0.002)^{* * *}$ \\
\hline \multirow[t]{2}{*}{ Car Class $=2$} & 0.031 & 0.034 \\
\hline & $(0.002)^{* * *}$ & $(0.002)^{* *}$ \\
\hline \multirow[t]{2}{*}{ Car Class $=3$} & 0.025 & 0.026 \\
\hline & $(0.002)^{* * *}$ & $(0.002)^{* * *}$ \\
\hline \multirow[t]{2}{*}{ Car Class $=4$} & 0.037 & 0.031 \\
\hline & $(0.002)^{* * *}$ & $(0.002)^{* * *}$ \\
\hline \multirow[t]{2}{*}{ Age } & 0.000 & -0.000 \\
\hline & $(0.000)$ & $(0.000)^{* *}$ \\
\hline \multirow[t]{2}{*}{ Female } & 0.028 & 0.026 \\
\hline & $(0.001)^{* * *}$ & $(0.001)^{* * *}$ \\
\hline French Name & 0.062 & 0.061 \\
\hline \multirow{2}{*}{ Arabic Name } & -0.074 & -0.072 \\
\hline & $0.003)^{* * *}$ & $(0.002)^{* * *}$ \\
\hline \multirow[t]{2}{*}{ Photo Shown } & 0.004 & 0.005 \\
\hline & $0.001)^{* * *}$ & $(0.001)^{* * *}$ \\
\hline \multirow[t]{3}{*}{ Plays Music } & 0.022 & 0.023 \\
\hline & $(0.001)^{* * *}$ & $(0.001)^{* * *}$ \\
\hline & -0.012 & -0.009 \\
\hline \multirow{3}{*}{ Allows Smoking } & $(0.002)^{* * *}$ & $(0.002)^{* * *}$ \\
\hline & -0.006 & -0.008 \\
\hline & $(0.002)^{* * *}$ & $(0.002)^{* * *}$ \\
\hline \multirow[t]{2}{*}{ Roundtrip } & 0.002 & -0.001 \\
\hline & $(0.001)$ & $(0.001)$ \\
\hline \multirow[t]{2}{*}{ Manual Confirmation } & -0.441 & -0.449 \\
\hline & $(0.002)^{* * *}$ & $(0.001)^{* * *}$ \\
\hline $\begin{array}{lll}N & Y\end{array}$ & 920789 & 919257 \\
\hline First-Stage F Stat & 1939.001 & 1079.877 \\
\hline
\end{tabular}

Notes: These robustness checks present alternative instruments with fraction of seats sold as the dependent variable. Column (1) reproduces Column (2) from Table 3 for comparison. This alternative instrument is based on the one week lag of average characteristics of other drivers on the same trip (excluding the driver in question), as described in the paper. Column (2) includes the average-other-price instrument from Column (2) from Table 3 and the average fraction of orange or red prices (i.e., not green prices) for other drivers on the trip in the prior week. 
Table B2: Robustness Checks Using Second Set of Alternative Instruments

\begin{tabular}{|c|c|c|}
\hline & (1) & (2) \\
\hline \multirow[t]{2}{*}{ Price } & -0.077 & -0.042 \\
\hline & $(0.002)^{* * *}$ & $(0.010)^{* * *}$ \\
\hline \multirow[t]{2}{*}{ Feedback Quantity } & 0.000 & 0.000 \\
\hline & $(0.000)^{* * *}$ & $(0.000)^{* * *}$ \\
\hline \multirow[t]{2}{*}{ Feedback Quality } & 0.002 & 0.002 \\
\hline & $(0.000)^{* * *}$ & $(0.000)^{* * *}$ \\
\hline \multirow[t]{2}{*}{ Intermediate } & 0.017 & 0.023 \\
\hline & $(0.001)^{* * *}$ & $(0.002)^{* * *}$ \\
\hline \multirow[t]{2}{*}{ Experienced } & 0.012 & 0.022 \\
\hline & $(0.002)^{* * *}$ & $(0.003)^{* * *}$ \\
\hline \multirow[t]{2}{*}{ Expert } & 0.012 & 0.027 \\
\hline & $(0.002)^{* * *}$ & $(0.005)^{* * *}$ \\
\hline \multirow[t]{2}{*}{ Ambassador } & 0.052 & 0.067 \\
\hline & $(0.002)^{* * *}$ & $(0.005)^{* * *}$ \\
\hline \multirow[t]{2}{*}{ Car Class $=1$} & 0.011 & 0.025 \\
\hline & $(0.003)^{* * *}$ & $(0.004)^{* * *}$ \\
\hline \multirow[t]{2}{*}{ Car Class $=2$} & 0.031 & 0.038 \\
\hline & $(0.002)^{* * *}$ & $(0.003)^{* *}$ \\
\hline \multirow[t]{2}{*}{ Car Class $=3$} & 0.025 & 0.026 \\
\hline & $(0.002)^{* * *}$ & $(0.002)^{* * *}$ \\
\hline \multirow[t]{2}{*}{ Car Class $=4$} & 0.037 & 0.026 \\
\hline & $(0.002)^{* * *}$ & $(0.004)^{* * *}$ \\
\hline \multirow[t]{2}{*}{ Age } & 0.000 & -0.000 \\
\hline & $(0.000)$ & $(0.000)^{* * *}$ \\
\hline \multirow[t]{2}{*}{ Female } & 0.028 & 0.023 \\
\hline & $(0.001)^{* * *}$ & $(0.002)^{* * *}$ \\
\hline French Name & 0.062 & 0.061 \\
\hline \multirow[t]{2}{*}{ Arabic Name } & -0.074 & -0.068 \\
\hline & $0.003)^{* * *}$ & $(0.003)^{* * *}$ \\
\hline \multirow[t]{2}{*}{ Photo Shown } & 0.004 & 0.005 \\
\hline & $0.001)^{* * *}$ & $(0.001)^{* * *}$ \\
\hline \multirow[t]{3}{*}{ Plays Music } & 0.022 & 0.025 \\
\hline & $(0.001)^{* * *}$ & $(0.001)^{* * *}$ \\
\hline & -0.012 & -0.006 \\
\hline \multirow{3}{*}{ Allows Pets } & $(0.002)^{* * *}$ & $(0.002)^{* * *}$ \\
\hline & -0.006 & -0.010 \\
\hline & $(0.002)^{* * *}$ & $(0.002)^{* * *}$ \\
\hline \multirow[t]{2}{*}{ Roundtrip } & 0.002 & -0.004 \\
\hline & $(0.001)$ & $(0.002)^{* *}$ \\
\hline \multirow[t]{2}{*}{ Manual Confirmation } & -0.441 & -0.458 \\
\hline & $(0.002)^{* * *}$ & $(0.005)^{* * *}$ \\
\hline $\begin{array}{lll}N & Y\end{array}$ & 920789 & 920789 \\
\hline First-Stage F Stat & 1939.001 & 36.942 \\
\hline
\end{tabular}

Notes: These robustness checks present alternative instruments with fraction of seats sold as the dependent variable. Column (1) reproduces Column (2) from Table 4 for comparison. These alternative instruments are based on the average characteristics of other drivers on the driver's modal trip (excluding the driver in question), as described in the paper. Column (2) includes two such instruments: average feedback quantity and average fraction of orange or red prices (i.e., not green prices), constructed from other drivers on the driver in question's modal trip in the same week. 


\section{Appendix C: Analysis of the Use of Manual Confirmation}

In this appendix, we present a regression analysis of manual confirmation. We find in the main analyses that manual confirmation is one of the strongest predictors of demand, reducing demand and revenue dramatically. As a result, we seek to understand which types of drivers use this option.

Appendix Table C1 displays the characteristics of the drivers choosing manual confirmation. Drivers with less experience and feedback are more likely to choose this option. Younger and male drivers, as well as drivers with an Arabic-sounding name tend to avoid manual confirmation (i.e., use "instant book"). The choice of manual confirmation can reflect a lack of experience with the platform, but also some tastebased screening from female and older drivers who may prefer to know with whom they will travel (even at the cost of sales). 
Table C1: Manual Confirmation Results

\begin{tabular}{|c|c|}
\hline & $(1)$ \\
\hline Feedback Quantity & $\begin{array}{l}-0.001 \\
(0.000)^{* * *}\end{array}$ \\
\hline Feedback Quality & $\begin{array}{l}-0.000 \\
(0.000)\end{array}$ \\
\hline Intermediate & $\begin{array}{l}-0.026 \\
(0.001)^{* * *}\end{array}$ \\
\hline Experienced & $\begin{array}{l}-0.026 \\
(0.001)^{* * *}\end{array}$ \\
\hline Expert & $\begin{array}{l}-0.038 \\
(0.001)^{* * *}\end{array}$ \\
\hline Ambassador & $\begin{array}{l}-0.058 \\
(0.002)^{* * *}\end{array}$ \\
\hline Car Class $=1$ & $\begin{array}{l}-0.017 \\
(0.002)^{* * *}\end{array}$ \\
\hline Car Class $=2$ & $\begin{array}{l}-0.031 \\
(0.002)^{* * *}\end{array}$ \\
\hline Car Class $=3$ & $\begin{array}{l}-0.028 \\
(0.001)^{* * *}\end{array}$ \\
\hline Car Class $=4$ & $\begin{array}{l}-0.014 \\
(0.002)^{* * *}\end{array}$ \\
\hline Age & $\begin{array}{l}-0.002 \\
(0.000)^{* * *}\end{array}$ \\
\hline Female & $\begin{array}{l}0.019 \\
(0.001)^{* * *}\end{array}$ \\
\hline French Name & $\begin{array}{l}0.005 \\
(0.001)^{* * *}\end{array}$ \\
\hline Arabic Name & $\begin{array}{l}-0.023 \\
(0.002)^{* * *}\end{array}$ \\
\hline Photo Shown & $\begin{array}{l}-0.025 \\
(0.001)^{* * *}\end{array}$ \\
\hline Plays Music & $\begin{array}{l}0.008 \\
(0.001)^{* * *}\end{array}$ \\
\hline Allows Pets & $\begin{array}{l}-0.008 \\
(0.001)^{* * *}\end{array}$ \\
\hline Allows Smoking & $\begin{array}{l}-0.001 \\
(0.002)\end{array}$ \\
\hline Roundtrip & $\begin{array}{l}0.008 \\
(0.001)^{* * *}\end{array}$ \\
\hline 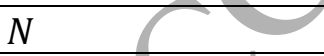 & 920789 \\
\hline
\end{tabular}

Notes: This table presents manual confirmation regressions. The dependent variable equals one if the driver chose to require manual confirmation on the trip, rather than allowing instant booking. The econometric specification is linear regression with trip fixed effects. 